\title{
Optimizing the mix design of cold bitumen emulsion mixtures using
}

\section{response surface methodology.}

Ahmed I. Nassar ${ }^{*}$, Nicholas Thom, Tony Parry.

Nottingham Transportation Engineering Centre, Department of Civil Engineering, Faculty of Engineering, University of Nottingham, University Park, Nottingham NG7 2RD, UK

* Corresponding author. Tel.: +44 (0) 1159513 953; fax: +44 (0) 1159513909.

E-mail address: evxan1@ @ottingham.ac.uk, ah.nassar@yahoo.com 


\section{Abstract}

Cold mix asphalt (CMA) has been increasingly recognized as an important alternative worldwide. One of the common types of CMA is cold bitumen emulsion mixture (CBEM). In the present study, the optimization of CBEM has been investigated, to determine optimum proportions to gain suitable levels of both mechanical and volumetric properties. A central composite design (CCD) with response surface methodology (RSM) was applied to optimize the mix design parameters, namely bitumen emulsion content (BEC), pre-wetting water content (PWC) and curing temperature (CT). This work aimed to investigate the interaction effect between these parameters on the mechanical and volumetric properties of CBEMs. The indirect tensile stiffness modulus (ITSM) and indirect tensile strength (ITS) tests were performed to obtain the mechanical response while air voids and dry density were measured to obtain volumetric responses.

The results indicate that the interaction of BEC, PWC and CT influences the mechanical properties of CBEM. However, the PWC tended to influence the volumetric properties more significantly than BEC. The individual effects of BEC and PWC are important, rather than simply total fluid content which is used in conventional mix design method. Also, the results show only limited variation in optimum mix design proportions (BEC and PWC) over a range of $\mathrm{CT}$ from $10^{\circ} \mathrm{C}$ to $30^{\circ} \mathrm{C}$. The variation range for optimum $\mathrm{BEC}$ was $0.42 \%$ and $0.20 \%$ for PWC. Furthermore, the experimental results for the optimum mix design were corresponded well with model predictions. It was concluded that optimization using RSM is an effective approach for mix design of CBEMs.

Keywords: Cold Bitumen Emulsion Mixtures; Response surface method; Analysis of variance; Optimum bitumen Emulsion content; Optimum Pre-wetting water content 


\section{Introduction}

Several benefits are gained from using cold mix asphalt (CMA) instead of hot mix asphalt (HMA). The benefits include conservation of materials and energy, preservation of the environment and reduction in cost $[1,2]$. One of the common types of CAM is cold bitumen emulsion mixture (CBEM). Although the advantages of CMAs are real, they attract relatively little attention and are considered inferior to HMA as structural layers due to their less satisfactory performance [3]. This may be at least partially due to the wide variation in available mix design procedures, tests and criteria. Some authorities and researchers have proposed mix design procedures, based on empirical formulae, laboratory tests or past experience [1, 4]. However, there is no global agreement on mixture design method or structural design methodology for CMAs [5]. Thus, it is clear that optimization of mixture parameters has to be made more consistent in order to promote the technology [4] whereas the variations in material proportions will generate differences in performance [6]. It is therefore essential to design and optimize mixture components in order to achieve appropriate properties $[4,7]$.

Most of the studies reported in the literature on CBEMs have focused on using the method adopted by the Asphalt Institute (Marshall Method for Emulsified Asphalt Aggregate Cold Mixture Design), with some modifications [1, 8]. There would therefore appear to be potential to explore the use of a statistical tool to optimize the mixture design of CBEMs.

In response to the above need, the present study has been undertaken in order to develop a performance based mix design incorporating a statistical approach using response surface methodology (RSM). RSM is used as the optimization technique to adjust the mixture parameters of CBEM to achieve acceptable mechanical strength and suitable volumetric 
properties. The study aimed to investigate the interaction effect of mixture parameters on the mechanical and volumetric properties of CBEM. RSM and a three-level factorial experimental design have been applied to satisfy these conditions. The central composite design (CCD) method has been used. CCD is a fractional factorial experimental design able to provide the relationship between responses and factors over a range of factor levels [9, $10]$.

RSM is regularly applied in disciplines such as concrete [11-13], material and mechanical engineering technologies [14-16]. Recently, there has been growing attention to the application of RSM in asphalt research [17-24]. Chávez-Valencia et. al. [17] also implemented RSM to evaluate the ageing phenomenon of bituminous binder in HMA. Haghshenas et. al. [18] studied the effects of frequency, temperature and their interaction, on rutting of HMA using RSM. Hamzah et. al. [19] used RSM to optimize the binder content of warm mix asphalt incorporating Rediset by evaluating the volumetric and strength properties of mixes. Kavussi et. al. [20] investigated the effect of aggregate gradation, hydrated lime content and Sasobit content on moisture damage of warm mix asphalt. An experimental study [21] used RSM to assess the effects of aggregate gradation and lime content on stripping of HMA in terms of the strength and stiffness. Also, Khodaii et. al. [22] evaluated the effects of aggregate gradation, lime content, Sasobit content and binder content on stripping potential of warm mix asphalt. RSM was used to investigate the effects of short term aging on asphalt binder rheological properties [23]. A laboratory study [24] assessed the properties of stone mastic asphalt mixtures incorporating waste polyethylene terephthalate using RSM.

There is therefore a potential benefit to apply RSM as an alternative approach for the optimization of mix design parameters in CBEMs. 


\section{Design of experiment using RSM}

Montgomery [9] defined RSM as a mathematical and statistical technique used for designing experiments in order to establish relationships between multiple factors and to optimize the relevant conditions of parameters in order to predict the best responses.

A fractional factorial design such as CCD is usually used in RSM [10]. It has been reported as a potentially useful approach which is able to provide a suitable functional relationship between the responses and the factors (i.e. input parameters) [21]. Design Expert 9.0.6.2 software (Stat-Ease Inc., Minneapolis, USA) was used for the design, mathematical modelling, statistical analysis, and optimization of the process parameters. Analysis of variance (ANOVA) was conducted in order to obtain the interaction among the different parameters and the influence of each individual parameter.

The appropriate regression model, recommended by $[9,10]$, was applied, as shown in the following equation:

$Y=\beta_{0}+\sum_{j=1}^{k} \beta_{j} X_{j}+\sum_{j=1}^{k} \beta_{j j} X_{j}^{2}+\sum_{i} \sum_{<j=2}^{k} \beta_{i j} X_{i} X_{j}+e_{i}$

Where $Y$ is the response, $X_{i}$ and $X_{j}$ are the parameters, $\beta$ is the regression coefficient, $k$ is the number of parameters included in the experiment, and $e$ is the random error.

There are two kinds of fluid inside CBEM, which are water and bitumen. The water content includes two sources of water: (1) a proportion of the bitumen emulsion content (BEC) and (2) the additional water in the mix, termed the pre-wetting water content (PWC). PWC is defined as the amount of water added to the mixture prior to the addition of bitumen 
emulsion. This addition is to improve the ability of bitumen emulsion to coat the aggregate and to improve the workability of the mixture.

An experimental program was undertaken in order to consider the effects of certain important parameters on CBEM mix design. The parameters (independent variables) considered were BEC, PWC and curing temperature (CT). BEC and PWC are presented as a percentage of total mass of dry aggregate. These three parameters together with their respective ranges were selected based on a preliminary study and extant literature $[4,25,26]$.

It is well known that the curing temperature significantly affects the properties of the CMAs [27-30]. Therefore, the CT was considered as a parameter in mix design, $10^{\circ} \mathrm{C}, 20^{\circ} \mathrm{C}$ and $30^{\circ} \mathrm{C}$ being taken to represent cold, moderate and warm climatic conditions, respectively. The ranges and the levels of all the parameters investigated are given in Table 1.

Table 1: Independent parameters and their coded levels for CCD.

\begin{tabular}{cccccc}
\hline \multirow{2}{*}{ Parameters } & \multirow{2}{*}{ Code } & \multirow{2}{*}{ Unit } & \multicolumn{3}{c}{ Coded parameter levels } \\
\cline { 4 - 6 } & & $\%$ & $\mathbf{- 1}$ & $\mathbf{0}$ & $\mathbf{+ 1}$ \\
\hline BEC & $\mathrm{X}_{1}$ & $\%$ & 0.0 & 2.0 & 7.0 \\
PWC & $\mathrm{X}_{2}$ & $\% .5$ & 20 & 30 \\
CT & $\mathrm{X}_{3}$ & ${ }^{\circ} \mathrm{C}$ & 10 & \\
\hline
\end{tabular}

(-1) refers low level; (0) refers to mean level; (+1) refers to high level

The literature shows that CMA design methods are similar to those of HMA, but with no universally accepted method or procedure [31]. There are two sets of tests commonly conducted when assessing HMA, mechanical tests and volumetric tests respectively. In the current study the responses considered represented the mechanical and the volumetric properties of CBEMs. Indirect tensile stiffness modulus (ITSM) and indirect tensile strength 
(ITS) were performed in order to evaluate the mechanical properties. Air voids and dry density were measured to assess the volumetric properties, calculated according to Asphalt Institute [5] recommendations.

The total number of experiments carried out was $20\left(=2^{\mathrm{k}}+2 \mathrm{k}+6\right)$, where $\mathrm{k}$ is the number of parameters $(\mathrm{k}=3)$. Fourteen different combinations were supplemented with six replicates of the mean case. The set of 14 mixes considered three levels of each studied parameter; all factors were varied in this way. The set of six replicates mixes considered the mid-level of each studied parameter; this point is often replicated in order to improve the precision of the experiment and minimize any possible sources of bias. The CCD matrix employed is presented in Table 2.

Table 2: Matrix of experimental design by CCD.

\begin{tabular}{lccc|c}
\hline \multirow{2}{*}{ Run No. } & \multicolumn{3}{c|}{ Mix design parameters } & \multirow{2}{*}{$\begin{array}{c}\text { Total fluid } \\
\text { content }(\%)\end{array}$} \\
\cline { 2 - 3 } & BEC $(\%)$ & PWC $(\%)$ & CT $\left({ }^{\circ} \mathrm{C}\right)$ & 8.50 \\
Mix 01 & 5.0 & 3.5 & 10 & 7.50 \\
Mix 02 & 7.0 & 0.5 & 10 & 10.5 \\
Mix 03 & 7.0 & 3.5 & 10 & 5.50 \\
Mix 04 & 5.0 & 0.5 & 10 & 8.00 \\
Mix 05 & 6.0 & 2.0 & 10 & 9.50 \\
Mix 06 & 6.0 & 3.5 & 20 & 6.50 \\
Mix 07 & 6.0 & 0.5 & 20 & 9.00 \\
Mix 08 & 7.0 & 2.0 & 20 & 8.00 \\
Mix 09 & 6.0 & 2.0 & 20 & 8.00 \\
Mix 10 & 6.0 & 2.0 & 20 & 8.00 \\
Mix 11 & 6.0 & 2.0 & 20 & 8.00 \\
Mix 12 & 6.0 & 2.0 & 20 & 7.00 \\
Mix 13 & 5.0 & 2.0 & 20 & 8.00 \\
Mix 14 & 6.0 & 2.0 & 20 & 8.00 \\
Mix 15 & 6.0 & 2.0 & 20 & 8.00 \\
Mix 16 & 6.0 & 2.0 & 30 & 10.50 \\
Mix 17 & 7.0 & 3.5 & 30 & 7.50 \\
Mix 18 & 7.0 & 0.5 & 30 & 8.50 \\
Mix 19 & 5.0 & 3.5 & 30 & 5.50 \\
Mix 20 & 5.0 & 0.5 & 30 & \\
\hline & & & & \\
\hline
\end{tabular}




\section{Material and experimental procedures}

\subsection{Aggregate}

The aggregate used in this study was crushed limestone. The aggregate gradation used is shown in Fig. 1. In order to ensure appropriate interlocking of the dense graded surface course mix, a gradation was selected according to BS 4987-1 [32].

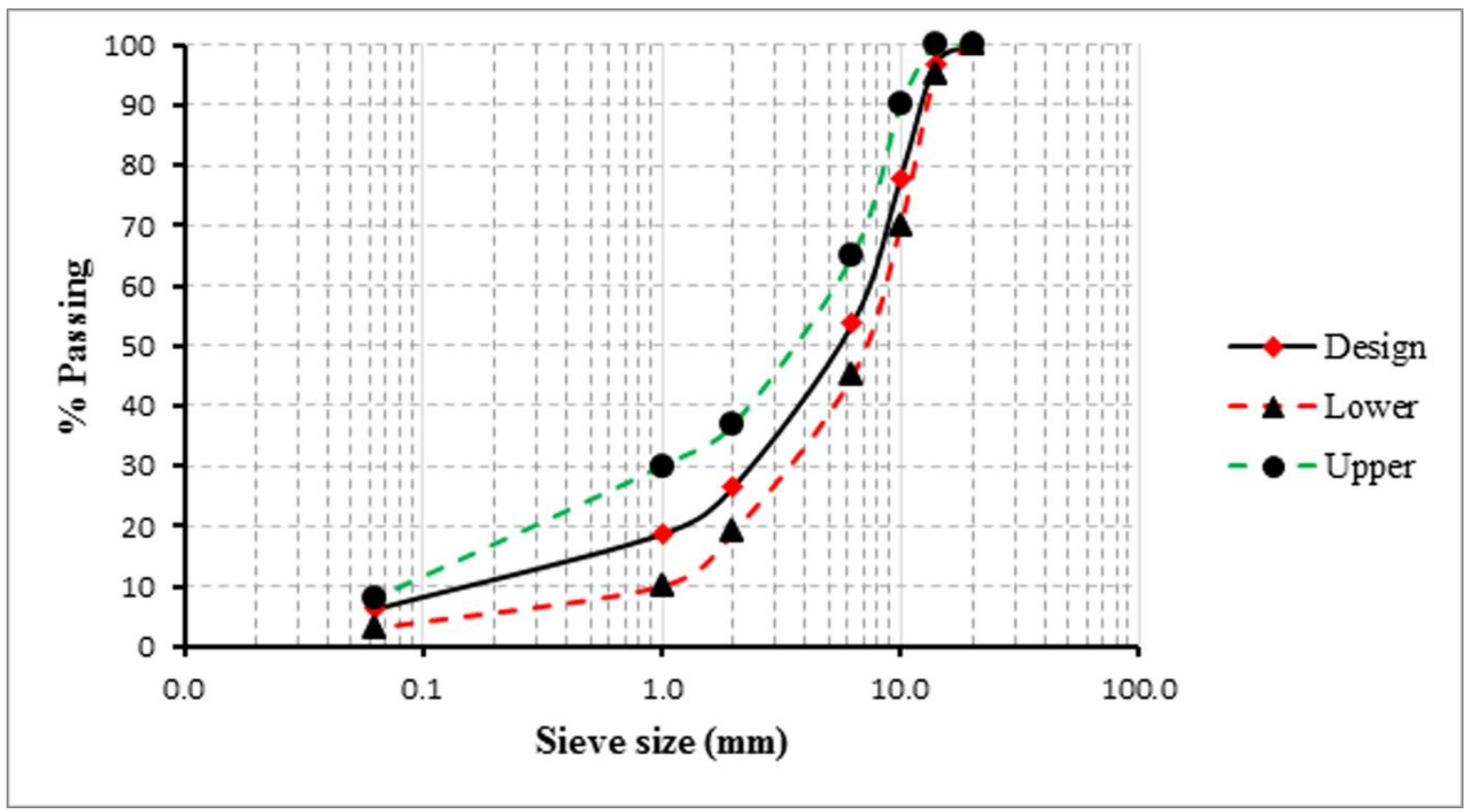

Fig. 1. Limestone aggregate gradation.

The physical properties of the limestone aggregate are shown in Table 3.

Table 3: Physical characteristics of limestone aggregate.

\begin{tabular}{lc}
\hline Properties & Value \\
\hline Density- Oven Dried & $2.68 \mathrm{Mg} / \mathrm{m}^{3}$ \\
Density- Saturated Surface Dried & $2.69 \mathrm{Mg} / \mathrm{m}^{3}$ \\
Density- Apparent & $2.70 \mathrm{Mg} / \mathrm{m}^{3}$ \\
Water Absorption & $0.4 \%$ \\
Aggregate Abrasion Value (AAV) & 11.0 \\
Polished Stone Value (PSV) & 31 \\
Los Angeles Coefficient (LA) & 28 \\
\hline
\end{tabular}




\subsection{Bitumen Emulsion}

The binder used was cationic slow setting bituminous emulsion (C60B5) to ensure high adhesion between aggregate particles [1]. The relevant properties of the selected bituminous emulsion are shown in Table 4.

Table 4: Bitumen emulsion properties.

\begin{tabular}{lcc}
\hline Property & Value & Standard \\
\hline Appearance & Black to dark brown liquid & \\
Breaking Behaviour & $>170$ & EN 13075-1 \\
Softening Point $\left({ }^{\circ} \mathbf{C}\right)$ & 52 & EN 1427 \\
Viscosity - Efflux time $\mathbf{2 m m}-\mathbf{4 0}^{\circ} \mathbf{C}(\mathbf{s e c})$ & $15-70$ & EN 12846 \\
Adhesiveness & $>90$ & EN13614 \\
Particle surface electric charge & Positive & EN 1430 \\
Bitumen content $(\boldsymbol{\%})$ & 60 & EN 1428 \\
Penetration $\left(\mathbf{d m m}^{\mathbf{3}}\right)$ & 47 & EN 1426 \\
Density $\left(\mathbf{g} / \mathbf{c m}^{\mathbf{3}}\right)$ & 1.016 & \\
\hline
\end{tabular}




\subsection{Sample manufacturing}

The mix proportions presented in Table 2 were used to prepare Marshall specimens.

The procedure followed for preparing the specimens was such that the PWC was first added to the dry batched mixture and mixed using a Sun and Planet mixer for $60 \mathrm{~s}$. This was followed by mixing using a spatula for 30s ensuring that the aggregate materials were thoroughly blended and wetted ready for the addition of the bitumen emulsion. The required emulsion was subsequently added and the mixture mixed for another 60s. To ensure homogeneity and consistency in the mix, the materials were then mixed by hand using a spatula for 30 s. These timings were found suitable for such mixes by [31, 33]. Impact compaction (Marshall Hammer) was utilized to compact the specimens; 75 blows applied to each face. The selection of 75 blows was made based on a pilot study performed to investigate the effective compaction effort for CBEMs. After compaction, the curing protocol followed was such that the specimens were left in the moulds for $24 \mathrm{hrs}$ (in a sealed condition) at the same ambient temperature before they were carefully extruded. After that, specimens were conditioned for 28 days in a thermostatically controlled air chamber at temperatures of $10^{\circ} \mathrm{C}, 20^{\circ} \mathrm{C}$, and $30^{\circ} \mathrm{C}$ as stated in Table 2.

\subsection{Laboratory testing program}

The mix design considered here relies on the information obtained from fundamental tests, which are used to evaluate the mixes proposed using CCD, as shown in Table 2. Two response types have been investigated in order to identify mixture performance, namely: mechanical responses and volumetric responses. 


\subsubsection{Mechanical responses}

The mechanical responses were evaluated by using ITSM and ITS tests.

\section{Indirect tensile stiffness modulus}

The ITSM is a non-destructive test used mainly to evaluate the stiffness modulus of bituminous mixes. Stiffness modulus is considered as an indicator of the structural behaviour of mixtures because it is related to the capacity of the material to distribute traffic loads. The test was carried out according to BS EN 12697-26 [34] and was performed under the conditions presented in Table 5. Four specimens per mix were tested under the same conditions.

Table 5: ITSM test conditions.

\begin{tabular}{lc}
\hline Item & Range \\
\hline Specimen diameter & $100 \pm 2 \mathrm{~mm}$ \\
Transient peak horizontal deformation & $3 \mu \mathrm{m}$ \\
Rise time & $124 \pm 4 \mathrm{~ms}$ \\
Poisson's ratio & 0.35 \\
Test temperature & $20{ }^{\circ} \mathrm{C}$ \\
Specimen thickness & $45-60 \mathrm{~mm}$ \\
Compaction & 75 blows/face \\
Specimen temperature conditioning & $20^{\circ} \mathrm{C}$ over the night before day of testing \\
\hline
\end{tabular}

\section{Indirect tensile strength}

The ITS test involved applying diametric compression with a constant deformation rate of $(50 \pm 2) \mathrm{mm} / \mathrm{min}$ to the samples between two loading strips, which creates tensile stresses along the vertical diametral plane causing a splitting failure. The test was conducted at $20^{\circ} \mathrm{C}$ using an INSTRON test equipment in accordance with BS EN 12697-23 [35]. 


\subsection{Volumetric responses}

It was demonstrated by Thanaya [1] that satisfactory volumetric properties are essential to the design of CBEMs. The volumetric properties of mixes were evaluated using the methodology proposed by the Asphalt Institute [5].

\section{Results and discussion}

A total of 80 Marshall specimens were produced for the 20 mixes proposed using CCD, four for each mix. The results are presented in Table 6 and discussed in the following paragraphs. 
Table 6: Experimental factors and experimental responses

\begin{tabular}{|c|c|c|c|c|c|c|c|c|c|c|c|c|c|}
\hline \multirow{2}{*}{\multicolumn{4}{|c|}{ Parameters }} & \multicolumn{10}{|c|}{ Responses } \\
\hline & & & & \multicolumn{6}{|c|}{ Mechanical Responses } & \multicolumn{4}{|c|}{ Volumetric Responses } \\
\hline $\begin{array}{l}\text { Run } \\
\text { No. }\end{array}$ & $\begin{array}{c}\text { BEC } \\
(\%)\end{array}$ & $\begin{array}{c}\text { PWC } \\
(\%)\end{array}$ & $\begin{array}{l}\text { CT } \\
\left({ }^{\circ} \mathrm{C}\right)\end{array}$ & $\begin{array}{c}\text { ITSM10 } \\
\text { days (MPa) }\end{array}$ & ڤ & $\begin{array}{c}\text { ITS dry } 28 \\
\text { days }(\mathrm{kPa})\end{array}$ & $\theta$ & $\begin{array}{c}\text { ITS wet } 28 \\
\text { days }(\mathrm{kPa})\end{array}$ & 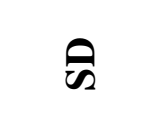 & $\begin{array}{c}\text { Dry density } \\
\left(\mathrm{kg} / \mathrm{cm}^{3}\right)\end{array}$ & ซ) & $\begin{array}{c}\text { Air voids } \\
(\%)\end{array}$ & 正 \\
\hline Mix 01 & 5.0 & 3.5 & 10 & 2141 & $(113.77)$ & 639 & $(31.24)$ & 444 & $(27.28)$ & 2232 & $(0.063)$ & 13.70 & $(0.072)$ \\
\hline Mix 02 & 7.0 & 0.5 & 10 & 2142 & $(265.68)$ & 688 & $(54.41)$ & 543 & $(4.56)$ & 2212 & $(14.45)$ & 13.85 & $(0.787)$ \\
\hline Mix 03 & 7.0 & 3.5 & 10 & 2551 & $(259.80)$ & 662 & $(29.22)$ & 477 & $(31.52)$ & 2203 & $(3.532)$ & 13.11 & $(0.156)$ \\
\hline Mix 04 & 5.0 & 0.5 & 10 & 1149 & $(244.79)$ & 401 & $(47.77)$ & 307 & $(11.86)$ & 2129 & $(11.08)$ & 18.01 & $(0.433)$ \\
\hline Mix 05 & 6.0 & 2.0 & 10 & 2859 & $(194.05)$ & 858 & (26.49) & 502 & $(41.46)$ & 2280 & $(0.645)$ & 11.09 & $(0.031)$ \\
\hline Mix 06 & 6.0 & 3.5 & 20 & 2928 & $(152.39)$ & 697 & (33.05) & 597 & $(30.92)$ & 2229 & (15.07) & 12.85 & $(0.569)$ \\
\hline Mix 07 & 6.0 & 0.5 & 20 & 1735 & $(230.94)$ & 614 & (74.77) & 524 & $(29.98)$ & 2167 & (7.11) & 15.44 & $(0.341)$ \\
\hline Mix 08 & 7.0 & 2.0 & 20 & 2999 & (234.07) & 1015 & (40.87) & 865 & (41.29) & 2257 & (12.67) & 11.27 & $(0.536)$ \\
\hline Mix 09 & 6.0 & 2.0 & 20 & 2953 & (161.68) & 924 & (42.38) & 798 & $(36.21)$ & 2243 & $(8.16)$ & 10.82 & $(0.296)$ \\
\hline Mix 10 & 6.0 & 2.0 & 20 & 2957 & (203.94) & 918 & (15.09) & 783 & (20.82) & 2253 & (7.04) & 10.85 & $(0.341)$ \\
\hline Mix 11 & 6.0 & 2.0 & 20 & 3055 & $(245.03)$ & 941 & $(31.25)$ & 788 & $(40.25)$ & 2286 & $(9.28)$ & 11.36 & $(0.325)$ \\
\hline Mix 12 & 6.0 & 2.0 & 20 & 2953 & (161.68) & 909 & $(28.15)$ & 773 & (35.01) & 2273 & $(8.14)$ & 10.92 & $(0.301)$ \\
\hline Mix 13 & 5.0 & 2.0 & 20 & 2576 & (181.15) & 910 & (33.95) & 790 & (30.33) & 2294 & $(1.81)$ & 11.075 & $(0.065)$ \\
\hline Mix 14 & 6.0 & 2.0 & 20 & 2988 & (161.68) & 928 & (42.38) & 793 & (33.58) & 2279 & $(9.28)$ & 11.36 & $(0.325)$ \\
\hline Mix 15 & 6.0 & 2.0 & 20 & 2955 & (203.94) & 934 & (15.09) & 778 & $(24.28)$ & 2248 & (7.04) & 10.85 & $(0.341)$ \\
\hline Mix 16 & 6.0 & 2.0 & 30 & 4313 & $(260.56)$ & 997 & (51.74) & 837 & (35.07) & 2276 & (3.79) & 11.24 & $(0.148)$ \\
\hline Mix 17 & 7.0 & 3.5 & 30 & 3306 & $(213.82)$ & 817 & (22.97) & 736 & $(3.74)$ & 2218 & (13.55) & 12.65 & $(0.708)$ \\
\hline Mix 18 & 7.0 & 0.5 & 30 & 3354 & (299.96) & 985 & $(65.47)$ & 861 & (24.98) & 2215 & (13.05) & 13.14 & $(0.475)$ \\
\hline Mix 19 & 5.0 & 3.5 & 30 & 3750 & $(230.55)$ & 705 & (69.08) & 601 & (38.91) & 2235 & $(8.16)$ & 13.59 & $(0.128)$ \\
\hline Mix 20 & 5.0 & 0.5 & 30 & 2192 & (109) & 503 & $(74.77)$ & 343 & $(30.81)$ & 2118 & $(8.12)$ & 18.34 & $(0.348)$ \\
\hline
\end{tabular}

* SD refers to Standard Deviation 


\subsection{Analysis of mechanical responses}

CMA performance is influenced by the time and temperature of the curing process [36-38].

Doyle et al. [36] found that it was necessary to vary both time and temperature of curing in order to represent the material achieved in the field. Logically, measurement of evaporated water will enable a better understanding of the performance of these mixtures. Therefore, periodically, specimen weights were recorded over 28 days. The results of average loss of water for all 15 individual mixes are shown in Fig. 2 , in which for example $\left(10^{\circ} \mathrm{C}\right.$ Mix $\left.5,3.5\right)$ refers to curing at $10^{\circ} \mathrm{C}$ with $5 \% \mathrm{BEC}$ and $3.5 \%$ PWC. The percentage of water loss was calculated based on the weight of specimens after demoulding directly. It can be observed that around $85 \%$ to $95 \%$ of the total evaporation occurs during the first 10 days and $5 \%$ to $15 \%$ through the remainder of the period.

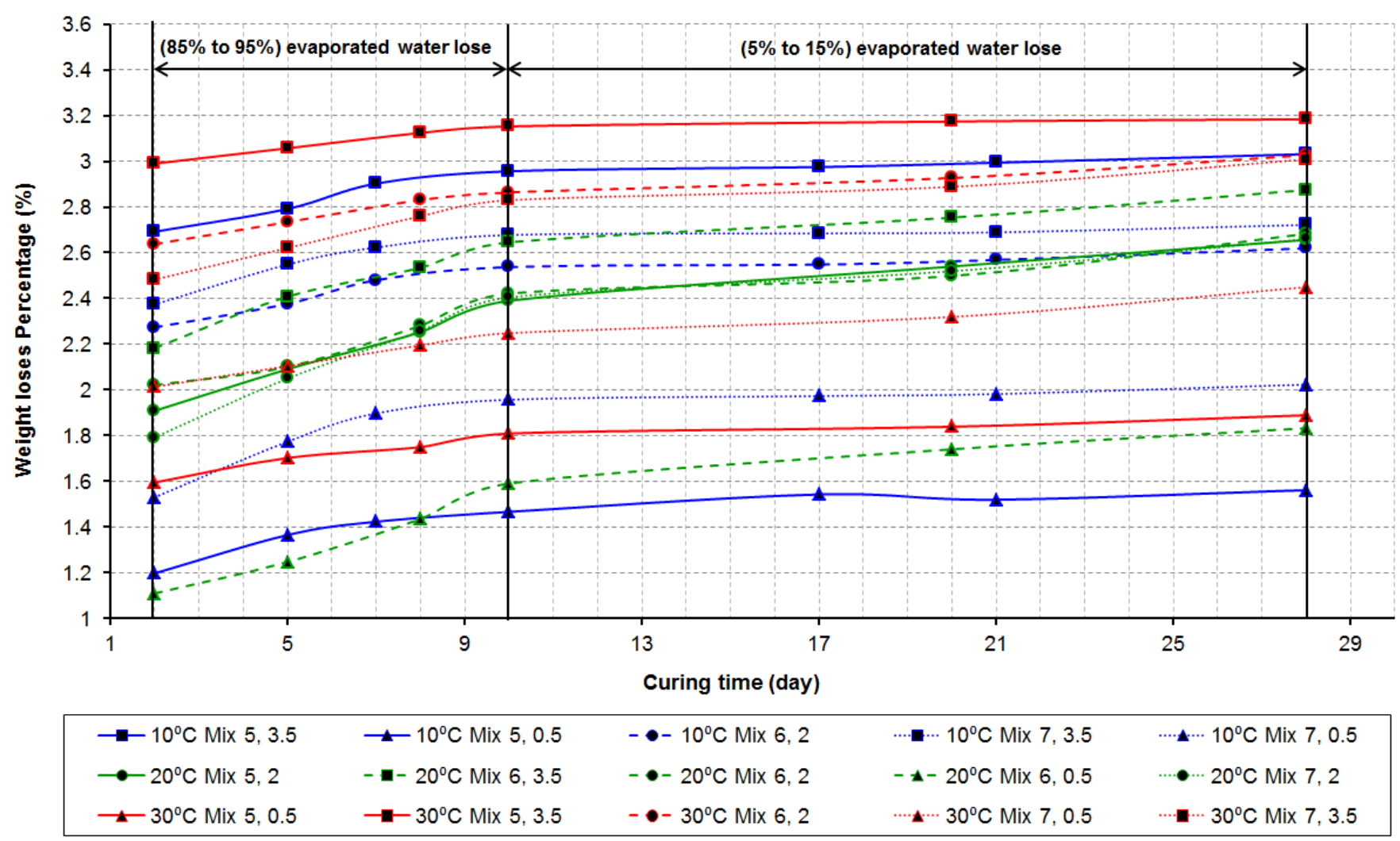

Fig. 2. Weight loss over curing period. 
The evaluation of stiffness was performed at 10 days and 28 days. This is broadly consistent with South African Bitumen Association [39] recommendation to evaluate CBEMs at room temperature at 7 days and 28 days.

\subsubsection{Indirect tensile stiffness modulus}

This test has often been used as an indicative test for ranking CBEMs during mix design [1, 31]. Following a conventional mix design method [5], the performance of CBEM was initially evaluated based on the relationship between total fluid content, which is the sum of BEC and PWC, and mechanical properties. The $\mathrm{ITSM}_{10}$ days and $\mathrm{ITSM}_{28}$ days are plotted against total fluid content in Fig. 3 in order to give a better understanding of the performance of CBEM. 

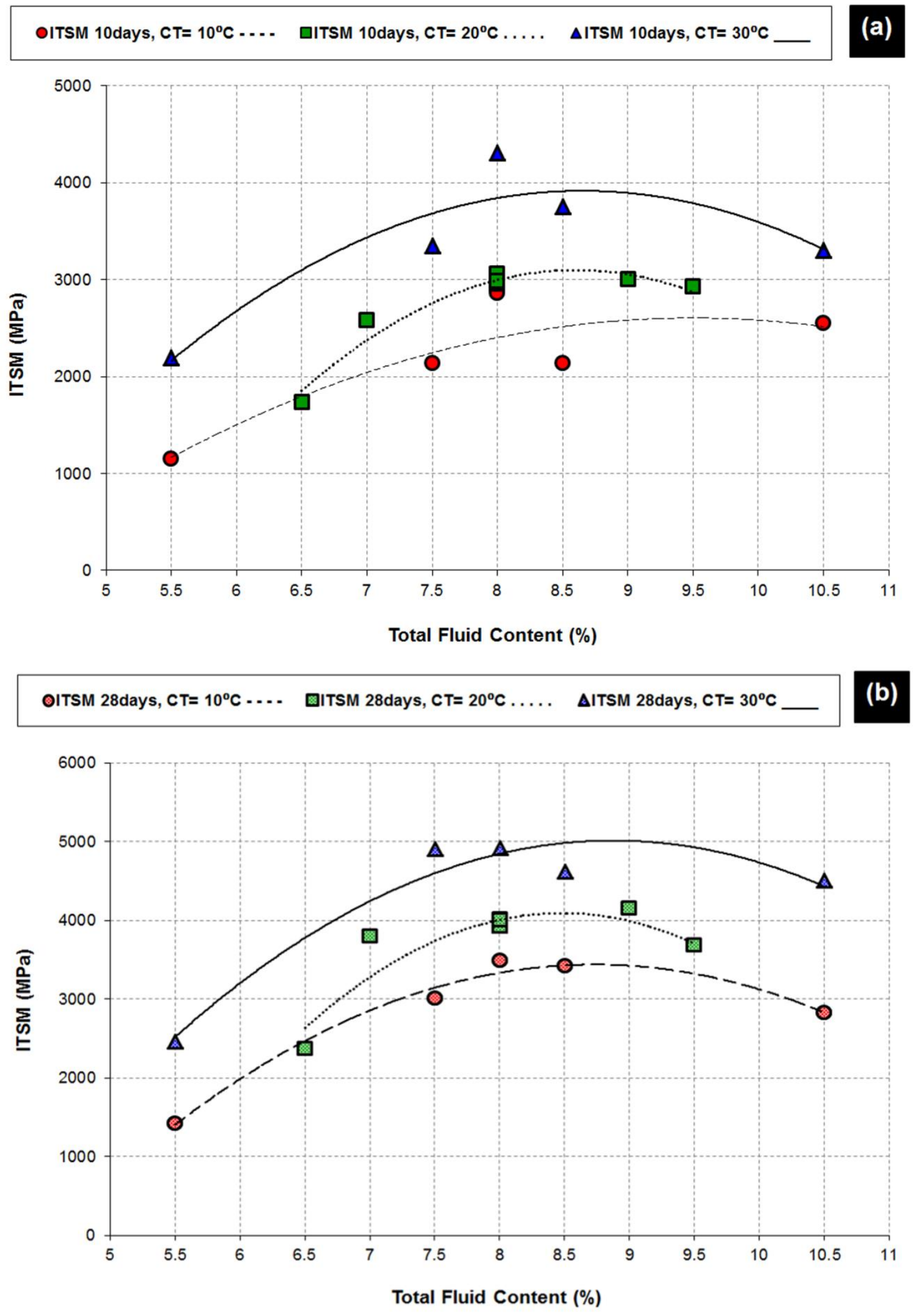

Fig. 3. The relation between ITSM and total fluid content of CBEMs under different CT after (a) 10 days and (b) 28 days 
As can be seen from Fig. 3, the stiffness values show the same trend at 10 and 28 days. Peak ITSM values occurred at between $8.5 \%$ to $9.5 \%$ total fluid content at both 10 and 28 days. Therefore, it is reasonable to propose that evaluation at 10 days will probably give the designer appropriate information to optimize the mix design of CBEM, although, a wide range of curing times has been used by different researchers [4]. Also, as expected, ITSM increases with CT at both 10 and 28 days. This is consistent with results obtained in previous studies $[1,6,40]$ and can at least partly be attributed to rapid water loss at higher temperature, which yields higher stiffness values with time. The results in Fig. 3 show that the lowest stiffness values were obtained from mixtures with the least total fluid content. This may be due to insufficient total fluid content in these mixes restricting the degree of compaction and increasing the air voids content in the mixture. It is worth noting the sensitivity of CBEMs' stiffness to the variation of individual mix components. Consequently, to assess the interactive relationship between the mix design parameters and the properties of CBEMs, RSM model has been used to generate a contour plot for ITSM $_{10 \text { days }}$ shown in Fig.4. 

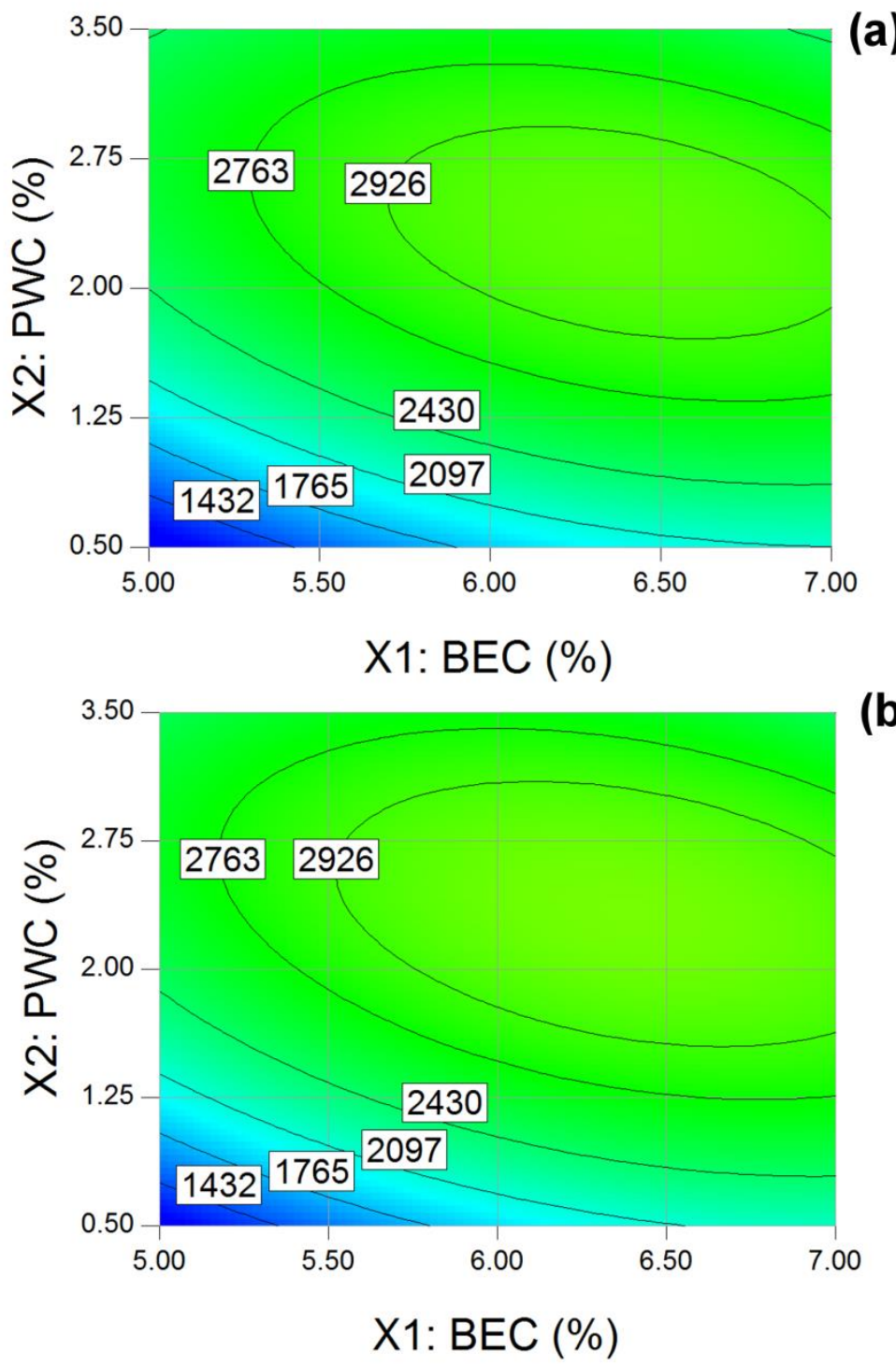

(b)

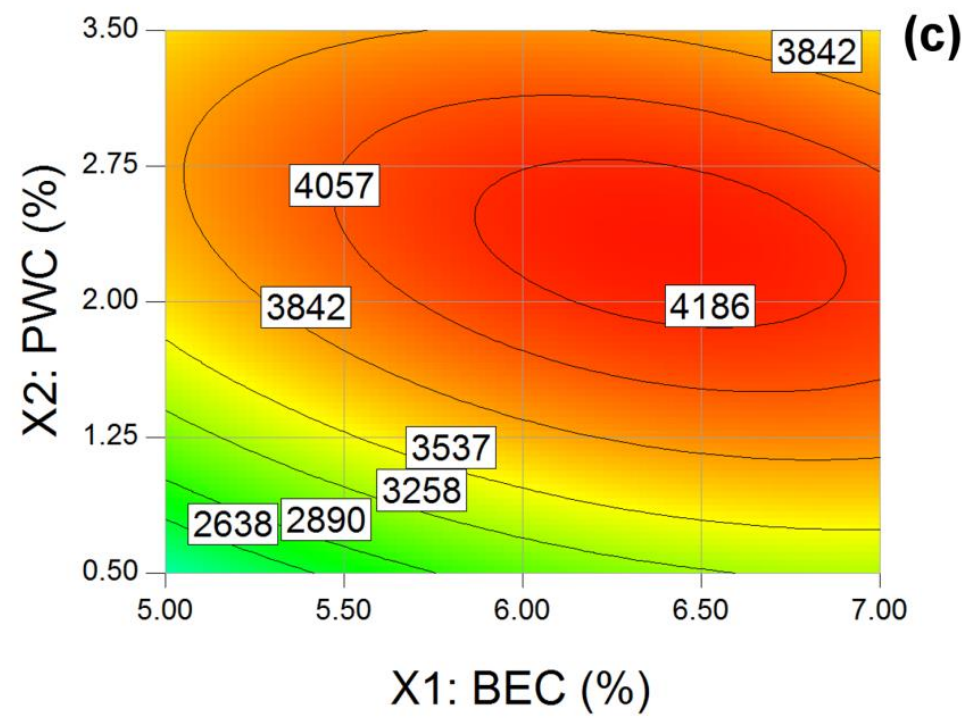

Fig. 4. Contour plots of ITSM 10 days versus BEC and PWC; (a) $\mathrm{CT}=10^{\circ} \mathrm{C}$, (b) $\mathrm{CT}=\mathbf{2 0}^{\circ} \mathrm{C}$ and (c) $\mathrm{CT}=30^{\circ} \mathrm{C}$. 
The results in Fig. 4 show the effect of BEC and PWC versus ITSM 10 days at different CT. From these contour plots ITSM 10 days values tend to increase markedly with increasing PWC from $0.50 \%$ to $2.75 \%$ and with increasing BEC from $5.0 \%$ to $6.5 \%$. However, ITSM $_{10}$ days markedly decreases when increasing PWC from $2.75 \%$ to $3.5 \%$ and increases slightly when increasing BEC from $6.5 \%$ to $7.0 \%$. Moreover, the results in Fig. 4 show that in reality the individual effects of BEC and PWC are important, rather than simply total fluid content. The response surface presented in Fig. 4 shows elliptical contours which is the pattern obtained when there are perfect interactions between independent variables [41, 42]. Accordingly, there is a region of optimum performance at around 6.0- 6.5\% BEC and 2.0- 2.5\% PWC, whereas ITSM is lower with different BEC/ PWC proportions, even at the same total fluid content. The effect of increasing CT is to increase ITSM (by approximately 1.25-1.60 times as the $\mathrm{CT}$ increases from $10^{\circ} \mathrm{C}$ to $30^{\circ} \mathrm{C}$ ) but optimum BEC and PWC are not significantly affected.

\subsubsection{Indirect tensile strength}

The ITS test was conducted on two sets of specimens: the first set (dry) was tested at 28 days immediately after curing; the second set (wet) was cured and then subjected to a vacuum (with $6.7 \mathrm{kPa}$ pressure) for $30 \pm 5$ minutes and immersed in a water bath for 3 days at $40^{\circ} \mathrm{C}$ before being tested. The reason for performing the ITS test on conditioned specimens is to take into consideration water damage as a criterion in mix design as recommended by several researchers $[1,40]$. A similar picture to that in ITSM is presented in Fig. 5; the results show that relation between total fluid content and ITS for dry and wet specimens. The strength values for both sets display similar behaviour to that seen for ITSM. The peak ITS values for all mixtures were consistently found to lie between $8 \%$ and $9 \%$ total fluid content which is a similar range as for ITSM. The effect of increasing CT is generally to increase ITS, although the difference in peak ITS between CTs of $20^{\circ} \mathrm{C}$ and $30^{\circ} \mathrm{C}$ is slightly. 

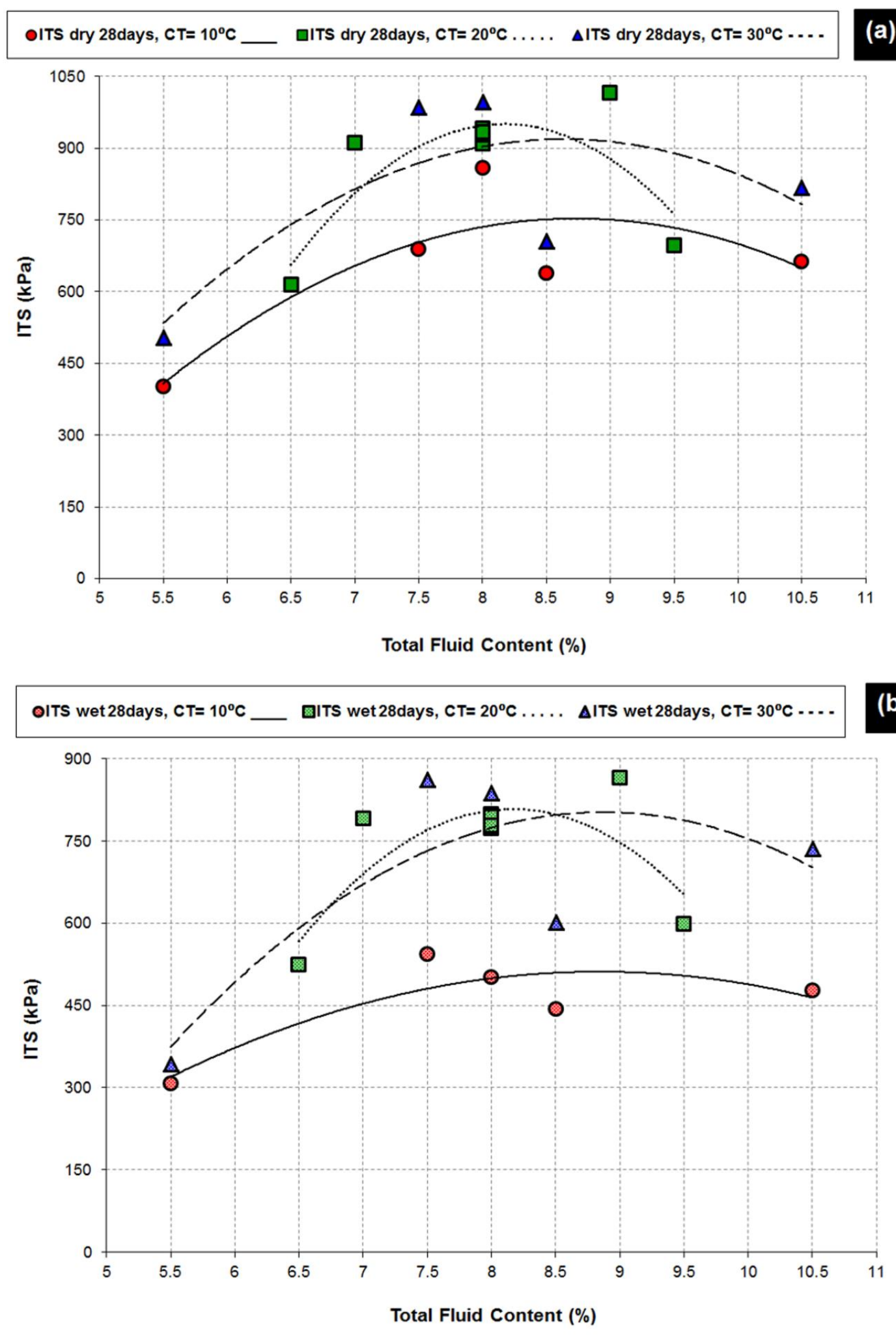

Fig. 5. The relation between ITS and total fluid content of CBEMs under different CT (a) dry condition and (b) wet condition.

Based on the developed model, Fig. 6 and 7 present the interaction effect of BEC and PWC on ITS values under different CT for dry and wet specimens, respectively. 

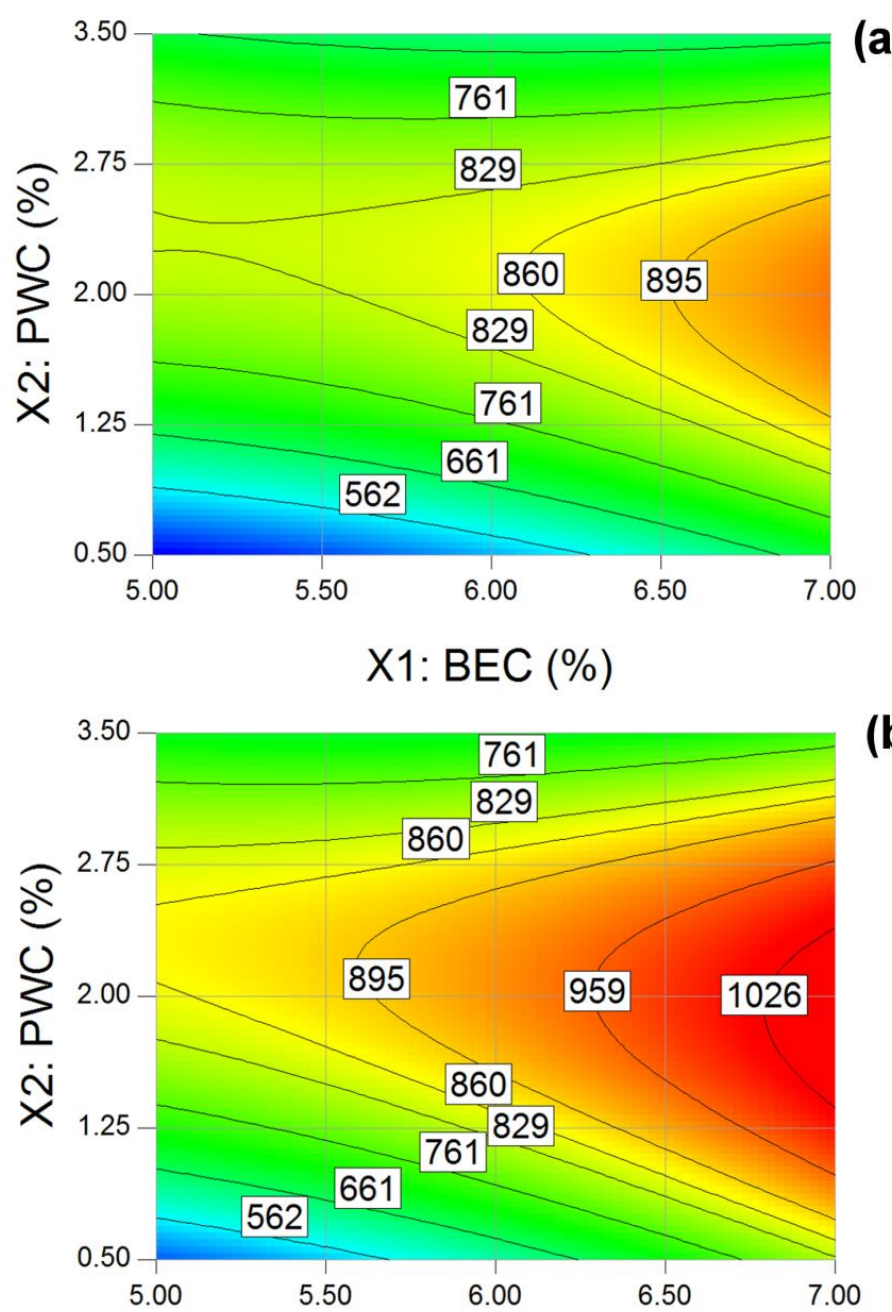

(b)

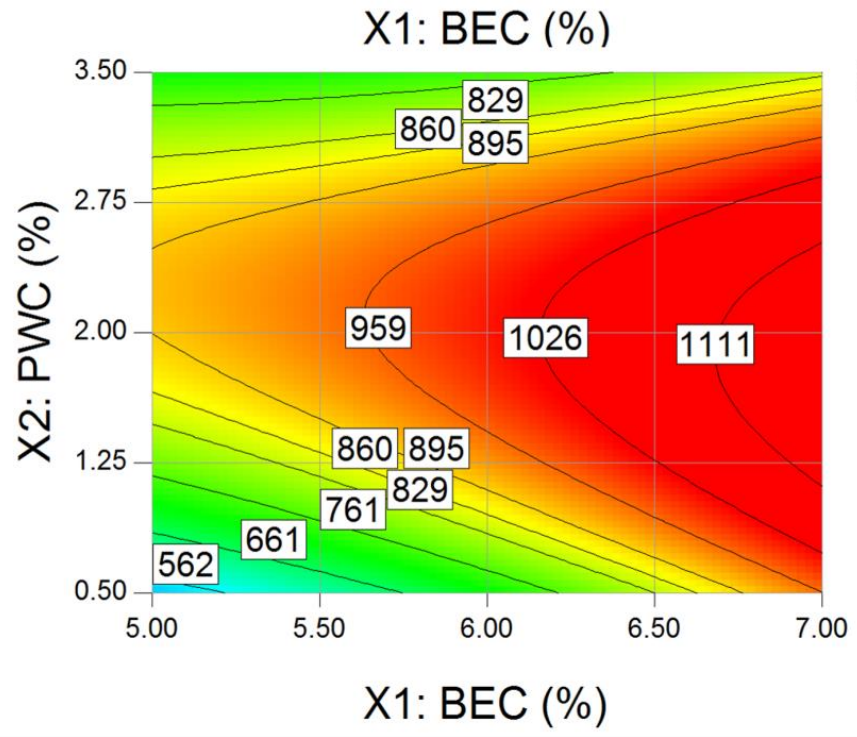

(c)

Fig. 6. Contour plots of ITS dry 28 days versus BEC and PWC; (a) CT $=10^{\circ} \mathrm{C}$, (b) CT $=20^{\circ} \mathrm{C}$ and $(\mathrm{c}) \mathrm{CT}=3^{\circ} \mathrm{C}$. 

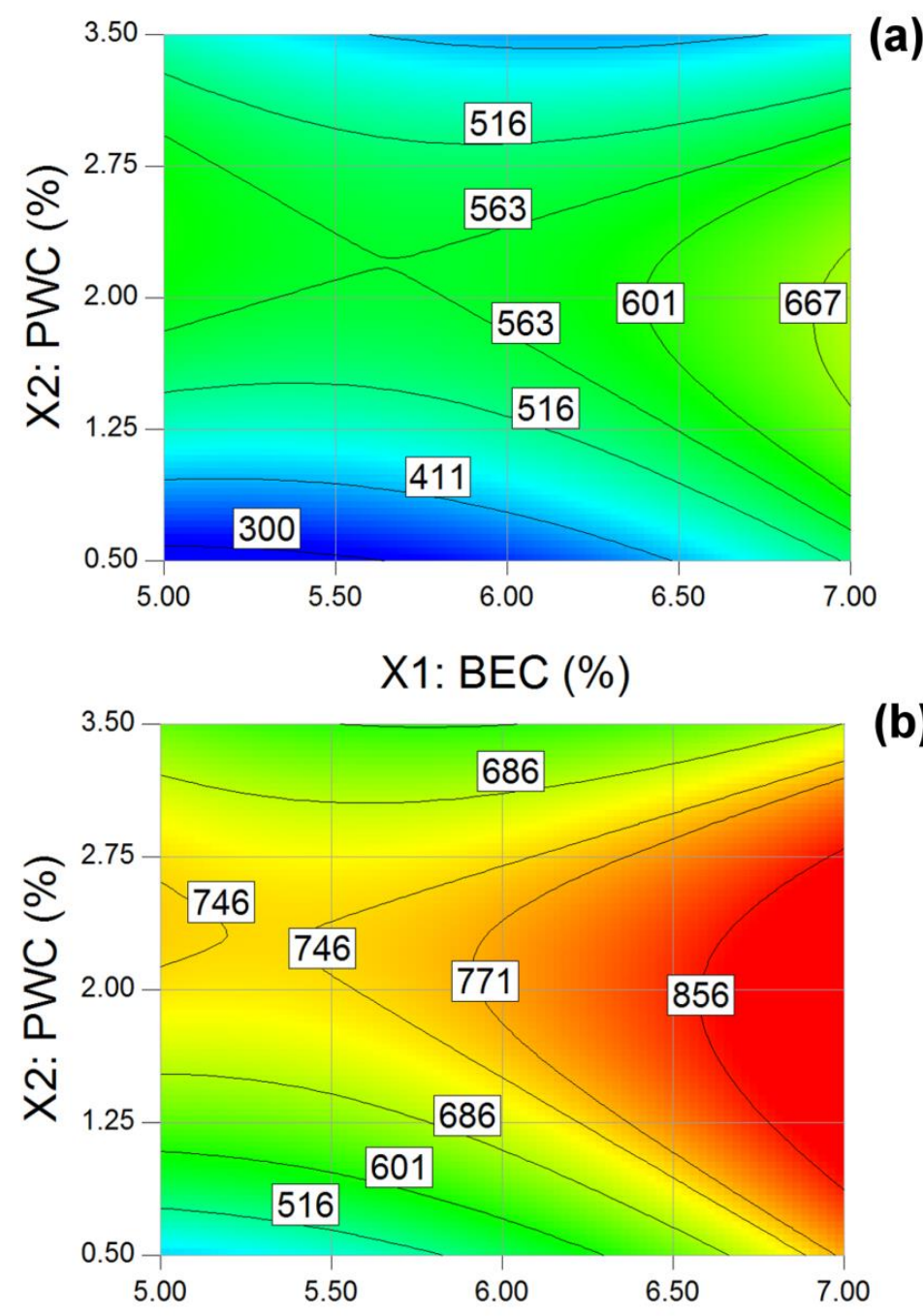

(b)

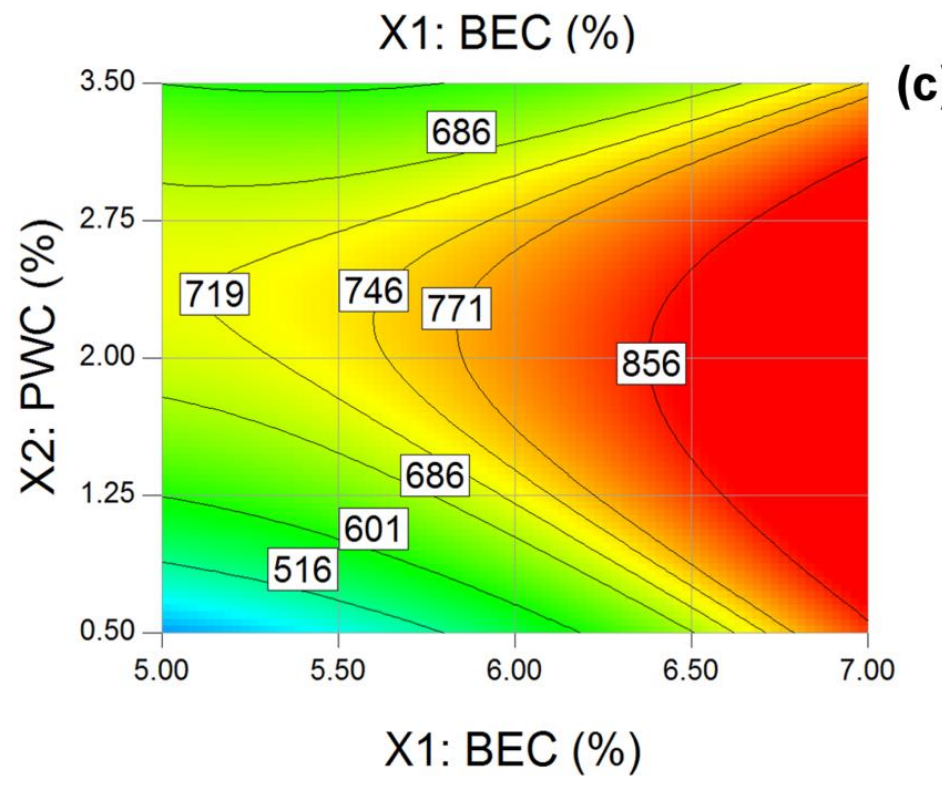

Fig. 7. Contour plots of ITS wet 28 days versus BEC and PWC; (a) $\mathrm{CT}=10^{\circ} \mathrm{C}$, (b) $\mathrm{CT}$ $=20^{\circ} \mathrm{C}$ and $(\mathrm{c}) \mathrm{CT}=30^{\circ} \mathrm{C}$. 
From Fig. 6 and 7, at a given CT, the results again indicate that ITS values significantly increase by increasing PWC from $0.50 \%$ to $2.375 \%$ and always increase with BEC while they markedly decrease by increasing the PWC from $2.375 \%$ to $3.5 \%$. Over all, increasing ITS was observed by increasing BEC and CT. The response surface presented in Fig. 6 and 7 shows distorted parabolic contours which are obtained in cases with fewer interactions between independent variables [41, 42]. This means that the optimum region is less clear than was the case of ITSM. Optimum PWC is between 1.5- 2.5\%, but optimum BEC may be around $6.5-7.0 \%$ or higher. The effect of CT on these optimum is again slight and both dry and wet data sets present a similar picture. A more general conclusion from both ITSM and ITS, is that the interaction of BEC and PWC (and to a lesser extent CT) is complex and that CBEMs must be carefully and accurately designed. This conclusion is consistent with the findings of Gómez-Meijide and Pérez [2].

\subsection{Analysis of volumetric responses}

A volumetric analysis was carried out to determine the void content and dry density present in each mix.

\subsubsection{Air voids:}

The results are presented in Table 6 . The air voids ranged from $10.82 \%$ to $18.34 \%$, higher than 9 to $14 \%$ suggested by others $[4,5,25]$. Fig. 8 shows the relation between the total fluid content and resulting air voids content. 


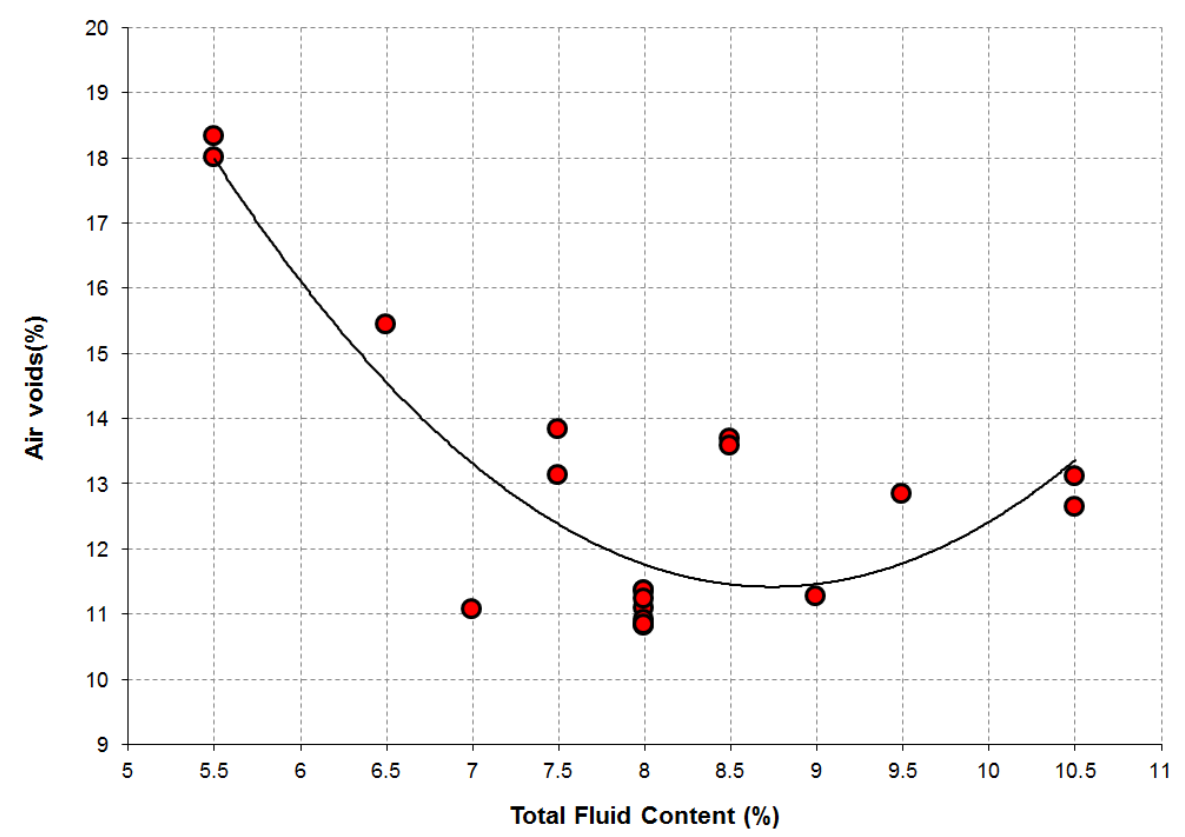

Fig. 8. The relation between air voids and total fluid content of CBEMs.

The highest values of air voids were observed at the lowest total fluid content, whereas the lowest air voids values were found at $8 \%$ to $9 \%$ total fluid content. The results imply the role of fluid inside the CBEM to determine the degree of compatibility of mixes.

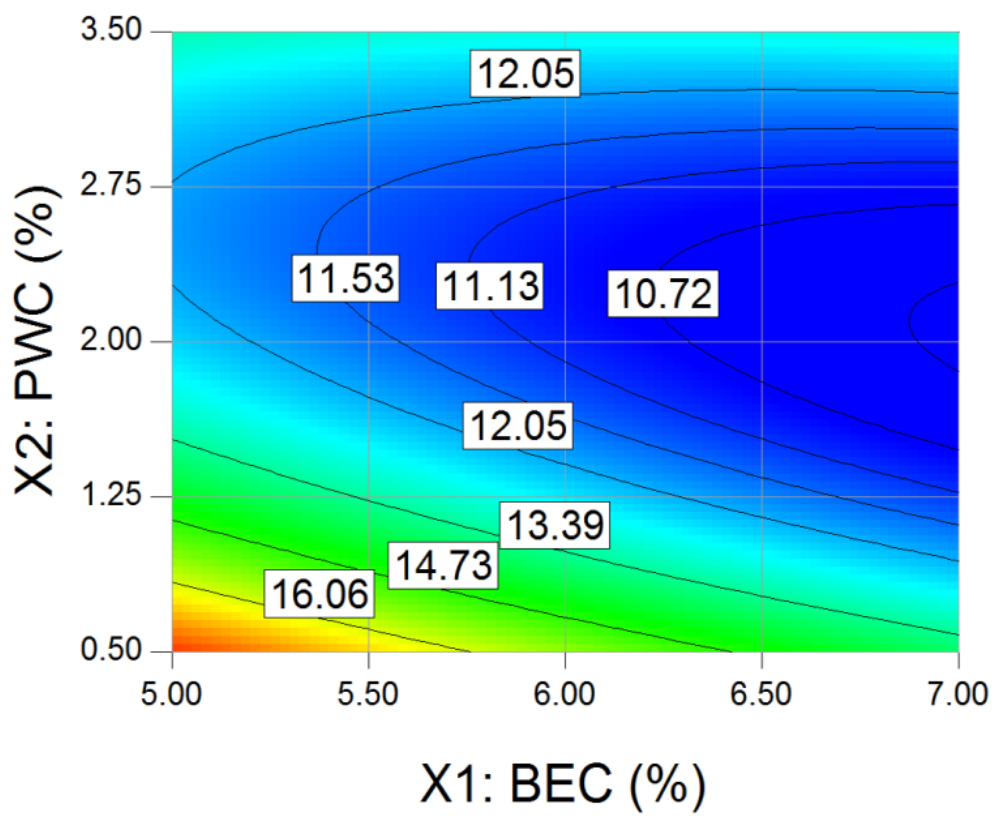

Fig. 9. Contour plot of air voids versus BEC and PWC. 
Based on RSM modelling, Fig. 9 presents a contour plot for the air voids measurement in which it is clear that the individual effects of BEC and PWC are both important. Air voids values decreased when increasing the BEC from $5.0 \%$ to $7.0 \%$ and markedly decreased when increasing the PWC from $0.50 \%$ to $2.0 \%$ then significantly increased when increasing PWC from $2.0 \%$ to $3.5 \%$. As for ITS there is a clear optimum region for PWC, about $1.5-2.5 \%$, but optimum BEC would appear to be at $7 \%$ or more and is therefore less clear on the plot. It is evident that PWC plays a key role in determining air voids in CBEM.

\subsubsection{Dry density:}

The dry density results are shown in Table 6. Fig. 10 presents the relation between dry density and total fluid content. Dry density values peak at around 8 to $9 \%$ total fluid content.

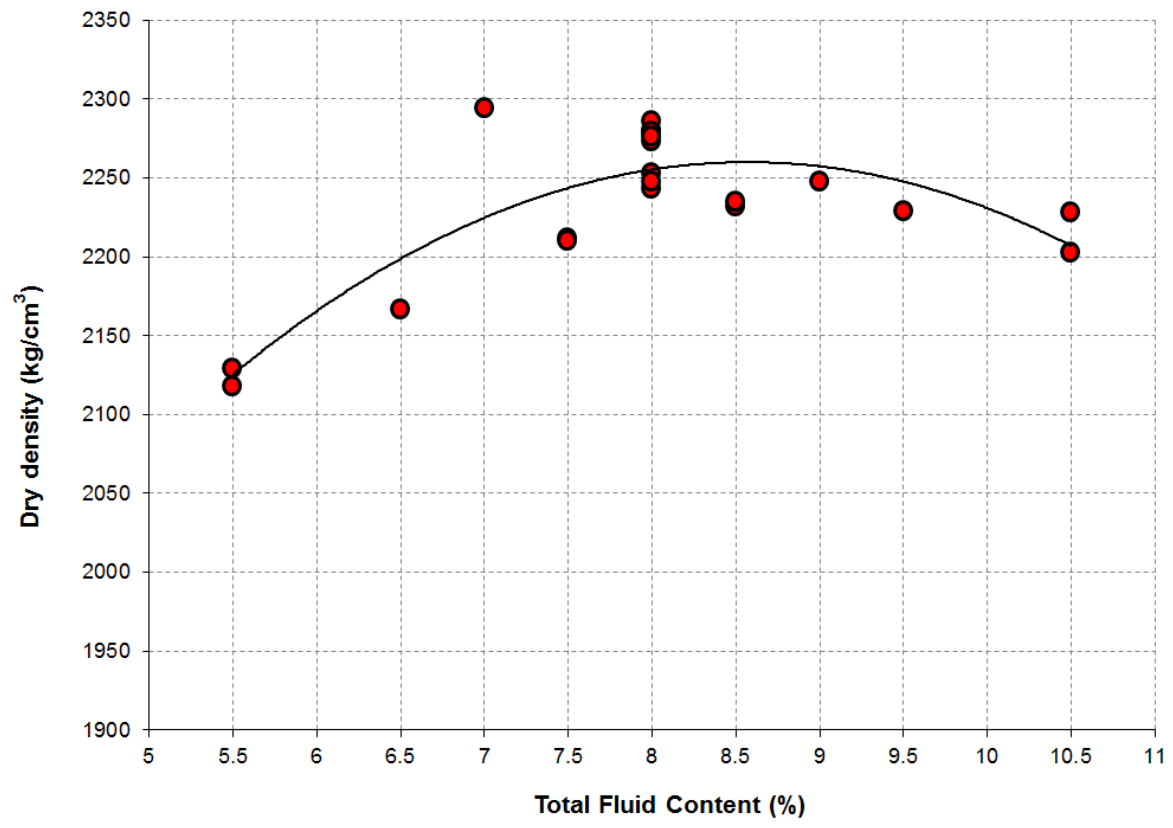

Fig. 10. The relation between dry density and total fluid content of CBEMs.

Based on RSM model, Fig. 11 presents a contour plot for dry density in terms of BEC and PWC. 


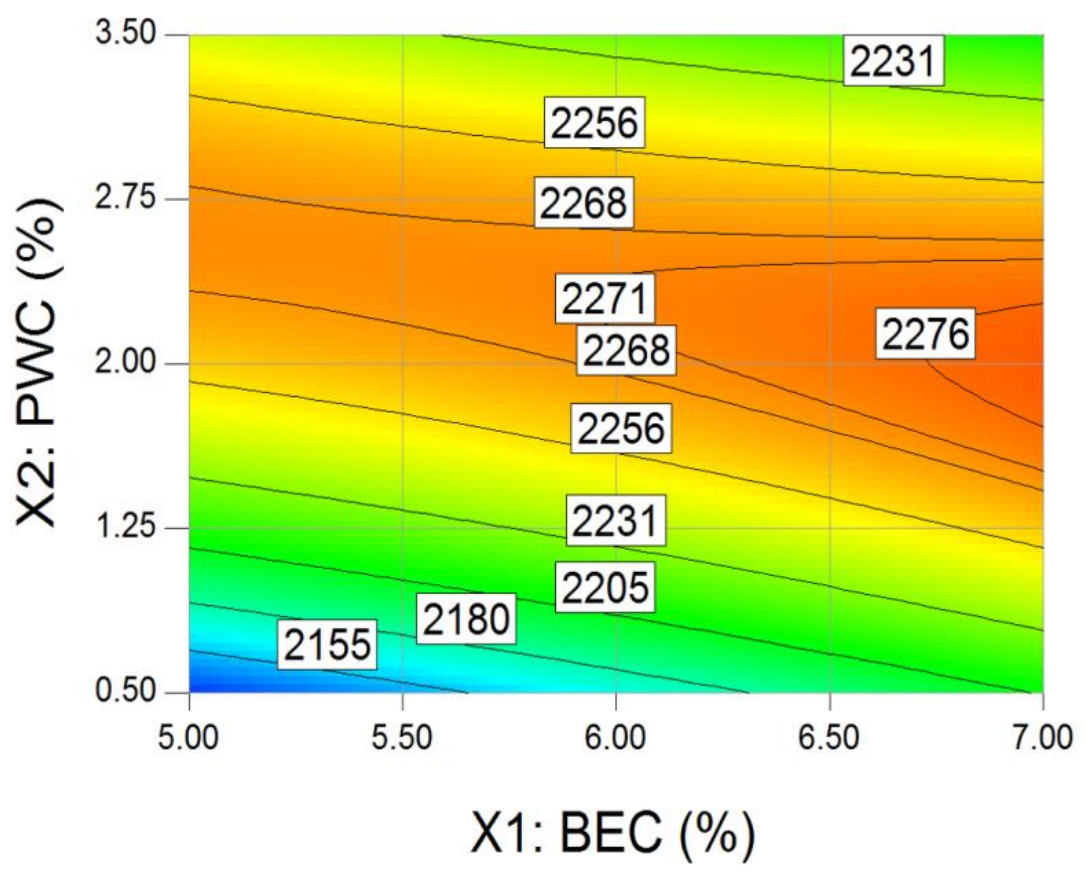

Fig. 11. Contour plot of dry density versus BEC and PWC.

Fig. 11 indicates that the dry density of CBEMs increased dramatically with an increase of PWC from $0.50 \%$ to $2.375 \%$ then decreased with an increase of PWC from $2.375 \%$ to $3.5 \%$. The dry density slightly increased when BEC increased from $5.0 \%$ to $7.0 \%$. The optimum PWC is in a narrow band either side of $2 \%$, while optimum BEC is less definite but appears to be close to $7 \%$. Low dry density corresponds to high air voids and poor mechanical performance, while the optimum for each measure approximately coincides.

\subsection{Statistical analysis of responses}

A statistical analysis was conducted to evaluate mix performance in terms of the abovementioned tests. A quadratic model was developed for prediction purposes. The quality of the developed model was evaluated based on the coefficient of determination, $R^{2}$ and also the standard deviation values. Determination coefficients were obtained as 0.96, 0.98, 0.95, 0.95 and 0.90 for ITSM $_{10}$ days, ITS dry 28 days, ITS wet 28 days, air voids and dry density, respectively. 
For a good model fit, the coefficient of determination should be a minimum of 0.80 . A high $R^{2}$ value close to 1.00 demonstrates a desirable and reasonable agreement between the calculated and observed results [43].

An additional tool used to evaluate the developed model was "adequate precision"' (AP). AP compares the range of the predicted values at the design points to the average prediction error. In this particular case, the $A P$ values of the models were $29.3,35.3,21.1,28.5$ and 17.6 for, respectively. They are greater than 4 and therefore confirm that the model can be used to navigate the space defined by the CCD [12].

The results of ANOVA analysis presented in Table 7 show that the models' F-values of 44.76, 94.77, 32.64, 77.77 and 36.82 and low P-values, which mean that the models are statistically significant for ITSM $_{10 \text { days, ITS dry }} 28$ days, ITS wet 28 days, air voids and dry density, respectively. Only a $0.01 \%$ chance exists that a model $F$-value of this magnitude can occur because of noise.

ANOVA results confirm that all the main parameters in the mix design of CBEMs (BEC $\left(X_{1}\right)$, PWC $\left(X_{2}\right)$ and CT $\left.\left(X_{3}\right)\right)$ have significant effects on mechanical response according to the $t$ test at a $5 \%$ significance level $(P<0.05)$. Both BEC and PWC have a significant effect on volumetric response, as shown in Table 7. Insignificant terms, which have limited influence $(P>0.1)$, were excluded from the study to improve the models. The lack of fit (LOF) F-test was also used to evaluate the adequacy of the model. LOF depicts the variation of the data 
Table 7: ANOVA for analysis of variance and adequacy of the quadratic model for responses.

\begin{tabular}{|c|c|c|c|c|c|c|c|}
\hline Response & SoD & SoS & DoF & MS & F-value & $P$-value $>\mathrm{F}$ & Comment \\
\hline \multicolumn{8}{|c|}{ ITSM 10 days } \\
\hline & Model & $8.88 \mathrm{E}+06$ & 7 & $1.27 \mathrm{E}+06$ & 44.76 & $<0.0001$ & \multirow{3}{*}{$\mathrm{SD}=168.34$} \\
\hline & $\mathrm{X}_{1}$ & $6.47 \mathrm{E}+05$ & 1 & $6.47 \mathrm{E}+05$ & 22.84 & 0.0004 & \\
\hline & $\mathrm{X}_{2}$ & $1.68 \mathrm{E}+06$ & 1 & $1.68 \mathrm{E}+06$ & 59.44 & $<0.0001$ & \\
\hline & $\mathrm{X}_{3}$ & $3.69 \mathrm{E}+06$ & 1 & $3.69 \mathrm{E}+06$ & 130.15 & $<0.0001$ & Mean $=2792.8$ \\
\hline & $\mathrm{X}_{1}^{2}$ & $1.78 \mathrm{E}+05$ & 1 & $1.78 \mathrm{E}+05$ & 6.27 & 0.0277 & $\mathrm{R}^{2}=0.96$ \\
\hline & $\mathrm{X}_{2}^{2}$ & $1.39 \mathrm{E}+06$ & 1 & $1.39 \mathrm{E}+06$ & 48.94 & $<0.0001$ & Adj. $R^{2}=0.94$ \\
\hline & $\mathrm{X}_{3}^{2}$ & $8.15 E+05$ & 1 & $8.15 \mathrm{E}+05$ & 28.76 & 0.0002 & \multirow[t]{2}{*}{$\mathrm{AP}=29.2$} \\
\hline & $\mathrm{X}_{1} \mathrm{X}_{2}$ & $5.99 \mathrm{E}+05$ & 1 & $5.99 \mathrm{E}+05$ & 21.14 & 0.0006 & \\
\hline & Residual & $3.40 \mathrm{E}+05$ & 12 & 28338.13 & \multirow{3}{*}{28.76} & \multirow{3}{*}{0.0010} & \\
\hline & Lack of Fit & $3.318 \mathrm{E}+05$ & 7 & 47402.40 & & & \\
\hline & Pure Error & 8240.83 & 5 & 1648.17 & & & \\
\hline \multicolumn{8}{|c|}{ ITS dry 28 days } \\
\hline & Model & $5.81 \mathrm{E}+05$ & 8 & 72628.92 & 94.77 & $<0.0001$ & \multirow{9}{*}{$\begin{array}{l}\mathrm{SD}=27.68 \\
\text { Mean }=802.25 \\
\mathrm{R}^{2}=0.98 \\
\text { Adj. } \mathrm{R}^{2}=0.97 \\
\mathrm{AP}=35.3\end{array}$} \\
\hline & $\mathrm{X}_{1}$ & $1.02 \mathrm{E}+05$ & 1 & $1.02 \mathrm{E}+05$ & 132.84 & $<0.0001$ & \\
\hline & $X_{2}$ & 10824.1 & 1 & 10824.1 & 14.12 & 0.0032 & \\
\hline & $\mathrm{X}_{3}$ & 57608.1 & 1 & 57608.1 & 75.17 & $<0.0001$ & \\
\hline & $\mathrm{X}_{1}^{2}$ & 2497.61 & 1 & 2497.61 & 3.26 & 0.0985 & \\
\hline & $\mathrm{X}_{2}^{2}$ & $2.49 \mathrm{E}+05$ & 1 & $2.49 \mathrm{E}+05$ & 325.16 & $<0.0001$ & \\
\hline & $\mathrm{X}_{1} \mathrm{X}_{2}$ & 50244.5 & 1 & 50244.5 & 65.56 & $<0.0001$ & \\
\hline & $X_{1} X_{3}$ & 10082 & 1 & 10082 & 13.16 & 0.004 & \\
\hline & $X_{2} X_{3}$ & 3960.5 & 1 & 3960.5 & 5.17 & 0.0441 & \\
\hline & Residual & 8430.39 & 11 & 766.4 & \multirow{3}{*}{9.99} & \multirow{3}{*}{0.0116} & \\
\hline & Lack of Fit & 7781.05 & 6 & 1296.84 & & & \\
\hline & Pure Error & 649.33 & 5 & 129.87 & & & \\
\hline
\end{tabular}

\section{ITS wet 28 days}

$\begin{array}{ccccccl}\text { Model } & 5.767 \mathrm{E}+005 & 8 & 72081.68 & 32.64 & <0.0001 & \mathrm{SD}=46.99 \\ \mathrm{X}_{1} & 99496.64 & 1 & 99496.64 & 45.06 & <0.0001 & \text { Mean=656.95 } \\ \mathrm{X}_{2} & 7623.12 & 1 & 7623.12 & 3.45 & 0.0901 & \mathrm{R}^{2}=0.95\end{array}$




$\begin{array}{ccccccc}\mathrm{X}_{3} & 1.223 \mathrm{E}+005 & 1 & 1.223 \mathrm{E}+005 & 55.38 & <0.0001 & \text { Adj. } \mathrm{R}^{2}=0.93 \\ \mathrm{X}_{1}^{2} & 10170.78 & 1 & 10170.78 & 4.61 & 0.0550 & \mathrm{AP}=21.1 \\ \mathrm{X}_{2}{ }^{2} & 1.163 \mathrm{E}+005 & 1 & 1.163 \mathrm{E}+005 & 52.66 & <0.0001 & \\ \mathrm{X}_{3}{ }^{2} & 25776.15 & 1 & 25776.15 & 11.67 & 0.0058 & \\ \mathrm{X}_{1} \mathrm{X}_{2} & 43087.27 & 1 & 43087.27 & 19.51 & 0.0010 & \\ \mathrm{X}_{1} \mathrm{X}_{3} & 18294.98 & 1 & 18294.98 & 8.29 & 0.0150 & \\ \text { Residual } & 24289.82 & 11 & 2208.17 & & & \\ \text { Lack of Fit } & 23837.05 & 6 & 3972.84 & 43.87 & 0.0004 & \\ \text { Pure Error } & 452.77 & 5 & 90.55 & & & \end{array}$

\section{Air voids}

\begin{tabular}{|c|c|c|c|c|c|c|c|}
\hline & Model & 92.97 & 4 & 23.24 & 77.77 & $<0.0001$ & \multirow{8}{*}{$\begin{array}{l}\mathrm{SD}=0.55 \\
\text { Mean }=12.78 \\
\mathrm{R}^{2}=0.95 \\
\text { Adj. } \mathrm{R}^{2}=0.94 \\
\mathrm{AP}=28.5\end{array}$} \\
\hline & $\mathrm{X}_{1}$ & 11.44 & 1 & 11.44 & 38.28 & $<0.0001$ & \\
\hline & $\mathrm{X}_{2}$ & 16.59 & 1 & 16.59 & 55.51 & $<0.0001$ & \\
\hline & $\mathrm{X}_{2}{ }^{2}$ & 57.27 & 1 & 57.27 & 191.66 & $<0.0001$ & \\
\hline & $\mathrm{X}_{1} \mathrm{X}_{2}$ & 7.66 & 1 & 7.66 & 25.65 & $<0.0001$ & \\
\hline & Residual & 4.48 & 15 & 0.30 & \multirow{3}{*}{6.12} & \multirow{3}{*}{0.0295} & \\
\hline & Lack of Fit & 4.14 & 10 & 0.41 & & & \\
\hline & Pure Error & 0.31 & 5 & 0.062 & & & \\
\hline \multicolumn{8}{|l|}{ Dry Density } \\
\hline & Model & 41661.05 & 4 & 10415.26 & 36.82 & $<0.0001$ & \multirow{8}{*}{$\begin{array}{l}\mathrm{SD}=16.82 \\
\text { Mean }=2232.35 \\
\mathrm{R}^{2}=0.90 \\
\text { Adj. } \mathrm{R}^{2}=0.88 \\
\mathrm{AP}=17.6\end{array}$} \\
\hline & $X_{1}$ & 940.90 & 1 & 940.90 & 3.33 & 0.0882 & \\
\hline & $\mathrm{X}_{2}$ & 7617.60 & 1 & 7617.60 & 26.93 & 0.0001 & \\
\hline & $X_{2}^{2}$ & 26718.05 & 1 & 26718.05 & 94.44 & $<0.0001$ & \\
\hline & $\mathrm{X}_{1} \mathrm{X}_{2}$ & 6384.50 & 1 & 6384.50 & 22.57 & 0.0003 & \\
\hline & Residual & 4243.50 & 15 & 282.90 & \multirow{3}{*}{0.82} & \multirow{3}{*}{0.6321} & \\
\hline & Lack of Fit & 2636.17 & 10 & 263.62 & & & \\
\hline & Pure Error & 1607.33 & 5 & 321.47 & & & \\
\hline
\end{tabular}

SoD: source of data; SoS: sum of squares; DoF: degree of freedom; MS: mean square. $\mathrm{X}_{1}=\mathrm{BEC}, \mathrm{X}_{2}=\mathrm{PWC}$ and $\mathrm{X}_{3}=\mathrm{CT}$

around the fitted model. For this investigation, the small $\mathrm{p}$ values for LOF ( $\mathrm{p}<0.05$ ), as presented in Table 7, show that except the dry density, which was insignificant, other 
responses including ITSM $_{10}$ days, ITS dry 28 days, ITS wet 28 days and air voids were significant. It is worth noting that while LOF values were significant, reasonable agreement between the predicted and adjusted $\mathrm{R}^{2}$ were found for all responses such that it can be concluded that the suggested models for all responses can be used to navigate satisfactorily into design space to find optimum mix design parameters. Similar observations were reported by [23, 24, 44].

The final regression models, in terms of the significant influencing factors, are expressed by the following second-order polynomial equations:

$$
\begin{aligned}
\operatorname{ITSM}_{10 \text { days }}= & -10708.36+3668.86 X_{1}+2630.56 X_{2}-157.01 X_{3}-254.13 X_{1}^{2} \\
& -315.61 X_{2}^{2}+5.44 X_{3}^{2}-182.41 X_{1} X_{2} \\
\text { ITS dry } 28 \text { day } & =369.05-199.68 X_{1}+864.71 X_{2}-10.74 X_{3}+27.93 X_{1}^{2}-124.02 X_{2}^{2} \\
& -52.83 X_{1} X_{2}+3.55 X_{1} X_{3}-1.48 X_{2} X_{3} \\
\text { ITS wet } & \\
& =134 \text { day } \\
& -0.96 X_{3}^{2}-48.92 X_{1} X_{2}+4.78 X_{1} X_{3}
\end{aligned}
$$

Air voids $=33.06-2.37 X_{1}-10.79 X_{2}+1.50 X_{2}^{2}+0.65 X_{1} X_{2}$

$$
\text { Dry Density }=2268.90+9.70 X_{1}+27.60 X_{2}-73.10 X_{2}^{2}-28.25 X_{1} X_{2}
$$

The significant interactions between variables are presented by 3D-surface plots, as shown in Fig. 12. These plots give more information on the interaction between mix design parameters 
affects the mechanical and volumetric responses. As clear in Table 7, where the interactive term is not statistically significant, their surface plots were not represented in Fig. 12.

The curvature of the surface plot in Fig. 12 (a) indicates that both BEC and PWC have interaction effect on ITSM $_{10}$ days. Also, Fig. 12 (b-f) depicts the effects of mix design parameters, BEC, PWC and CT, on ITS values in both conditions (dry and wet). Based on the curvature of the surface plots, it is clear that BEC and PWC have the more powerful effect. However, the other interactions of parameters BEC and CT and PWC and CT are clearly observed on the ITS results, which means that ITS is influenced more strongly than ITSM in terms of mix design parameters. This is further confirmed by the result presented in section 4.1.2. Fig 12 ( $g$ and $\mathrm{h}$ ) presents the interaction effects of BEC and PWC on the volumetric properties of CBEMs. The curvature of the surface plot in Fig. 12 ( $\mathrm{g}$ and $\mathrm{h}$ ) shows that PWC tended to influence the volumetric responses more markedly than BEC. 
(a)
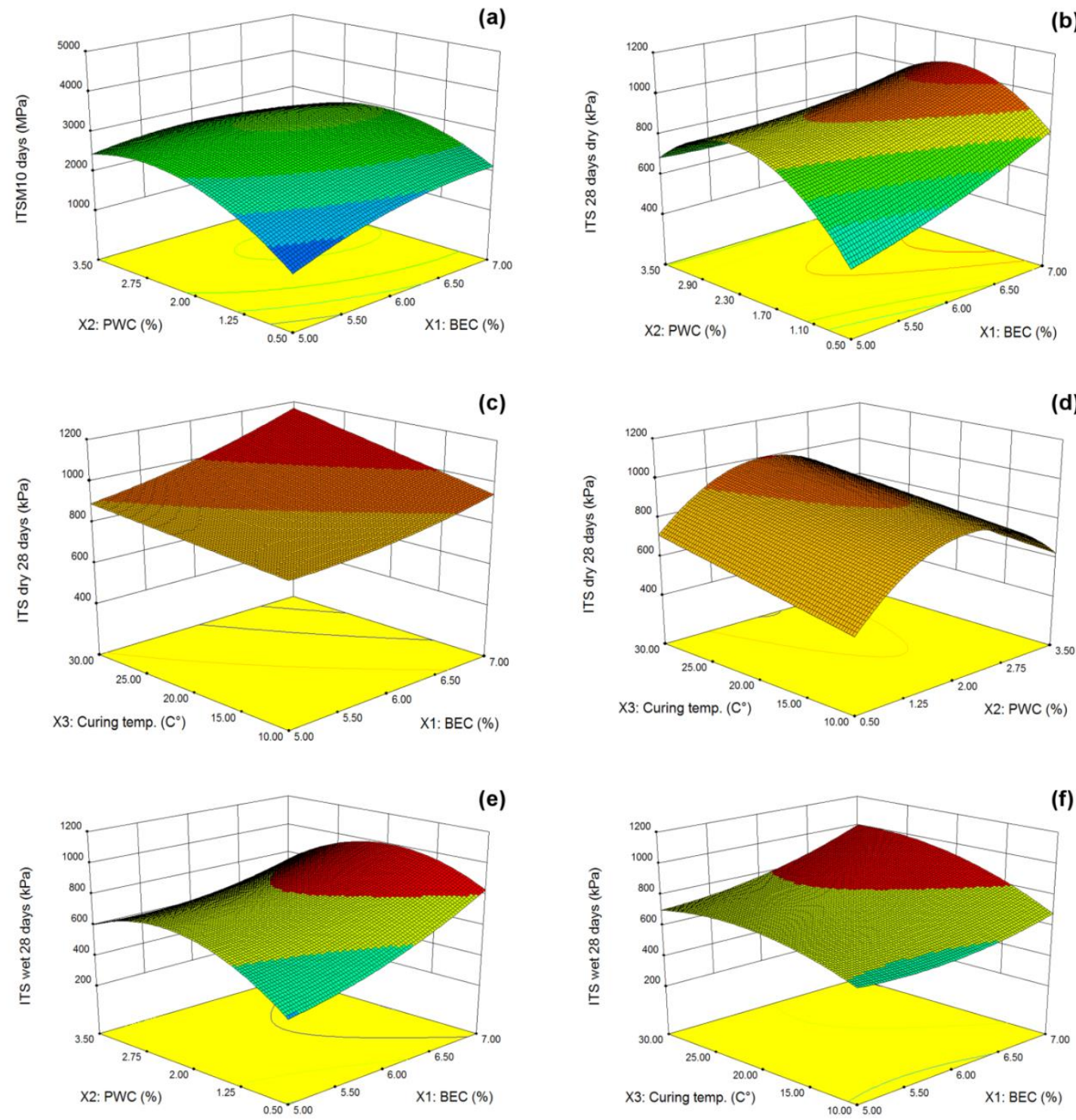

(g)

(h)
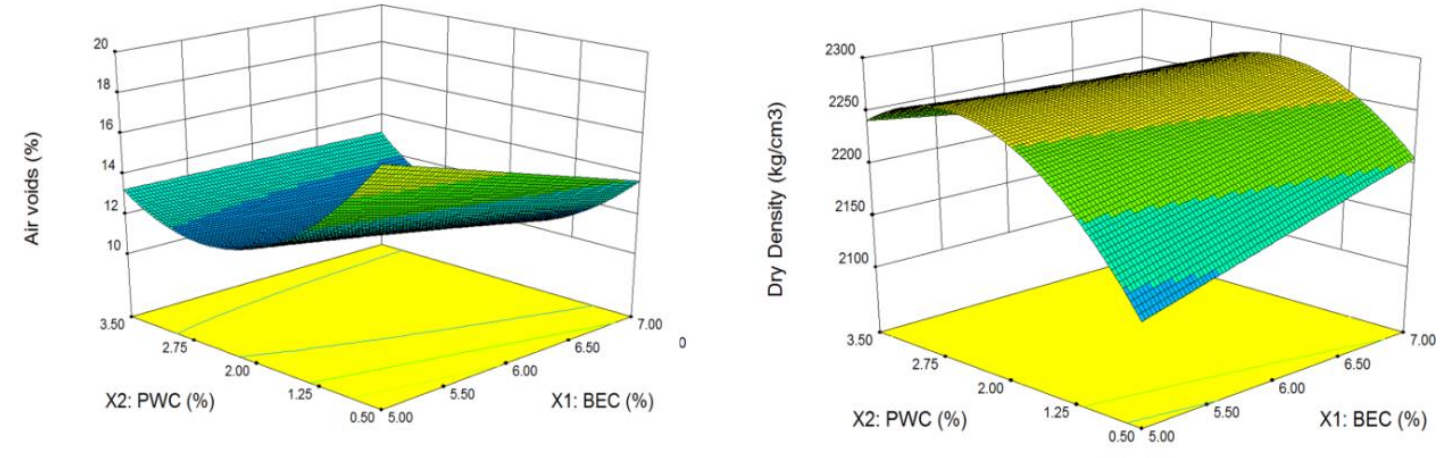

Fig. 12. 3D-surface plots of ITSM 10 days, ITS dry 28 days, ITS wet 28 days, air voids and dry density. (a) ITSM 10 days versus BEC and PWC. (b) ITS dry 28 days versus BEC and PWC. (c) ITS dry 28 days versus BEC and CT. (d) ITS dry28 days versus PWC and CT. (e) ITS wet 28 days versus BEC and PWC. (f) ITS wet 28 days versus BEC and CT. (g) Air voids versus BEC and PWC. (h) Dry density versus BEC and PWC. 


\subsection{Optimization the mix design components}

An optimization process was carried out to determine the optimum value of BEC, and PWC under different CTs, using the Design Expert 9.0.6.2 software (Stat-Ease Inc., Minneapolis, USA). According to the software optimization step, the desired goal for each mix design parameter (BEC and PWC) was chosen within the range shown in Table 1. The desirable mechanical responses (ITSM 10 days, ITS dry 28 days and ITS wet 28 days) were defined as being a maximum to achieve the highest performance, the desirable air voids was defined as a minimum and desirable dry density was defined as a maximum in order to achieve a dense mixture with the lowest value of air voids. The derived second order polynomial models were used to interpolate the mix design parameters within the range and based on the desired responses. The results are presented in Table 8 .

Table 8: The optimum BEC and PWC at different CT with their responses.

\begin{tabular}{|c|c|c|c|c|}
\hline Items & \multicolumn{3}{|c|}{ Model prediction } & Laboratory experiment \\
\hline $\mathrm{CT}\left({ }^{\circ} \mathrm{C}\right)$ & $\mathrm{T}=10^{\circ} \mathrm{C}$ & $\mathrm{T}=20^{\circ} \mathrm{C}$ & $\mathrm{T}=30^{\circ} \mathrm{C}$ & $\mathrm{T}=20^{\circ} \mathrm{C}$ \\
\hline $\operatorname{BEC}(\%)$ & 7.00 & 6.75 & 6.58 & 6.75 \\
\hline $\operatorname{PWC}(\%)$ & 1.96 & 2.12 & 2.16 & 2.12 \\
\hline ITSM $_{10 \text { days }}(\mathbf{M P a})$ & 2936 & 3063 & 4235 & 3049 \\
\hline ITS dry 28 days (kPa) & 946 & 1015 & 1086 & 1000 \\
\hline ITS wet 28 days (kPa) & 684 & 883 & 894 & 889 \\
\hline Air voids (\%) & 10.02 & 10.26 & 10.42 & 10.34 \\
\hline Dry density $\left(\mathrm{kg} / \mathrm{cm}^{3}\right)$ & 2279 & 2276 & 2275 & 2278 \\
\hline
\end{tabular}

An additional laboratory experiment was carried out to validate the optimum mix design proportions obtained by the RSM model. The experimental work was performed at CT equal to $20^{\circ} \mathrm{C}$. The results in Table 8 demonstrate that the experimental results are close to the predicted results by the developed model at $\mathrm{CT}$ of $20^{\circ} \mathrm{C}$. 
The results in Table 8 show a limited variation of optimum mix design proportions (BEC and PWC) over the range of $\mathrm{CT}$ from $10^{\circ} \mathrm{C}$ to $30^{\circ} \mathrm{C}$. The maximum variation of $\mathrm{BEC}$ is $0.42 \%$ and $0.20 \%$ for PWC. The total fluid content $(\mathrm{BEC}+\mathrm{PWC})$ for the optimized mixes lies within the range from $8.74 \%$ to $8.96 \%$. Therefore, it can be concluded that the optimum proportions (BEC and PWC) tend to be only slightly influenced by CT. Overall, the results are comparable with those published by other authors about the mix design of CBEM $[1,26$, 31].

\section{Conclusions}

The current research introduces a novel performance based mix design approach for CBEM involving mechanical and volumetric properties. A statistical approach was adopted in order to optimize the mix design parameters using RSM. Based on the laboratory experiments and analyses, the following conclusions can be drawn:

1. An alternative mix design approach for CBEMs was investigated using RSM. This approach involves the mechanical and volumetric properties. It was statistically demonstrated that the alternative approach output results were consistent with the laboratory tests.

2. The RSM approach offers a more comprehensive view of the effect of the variation of each mix design parameter on the mechanical and volumetric responses of CBEMs than would otherwise be the case. It has the advantage that all parameters are investigated at one time.

3. The individual effects of BEC and PWC are important, rather than simply total fluid content which is used in conventional mix design method. The results show a lower 
strength/ stiffness of CBEM at the same total fluid content and with different BEC/ PWC proportions.

4. The evaluation of stiffness modulus of CBEMs after 10 days is likely to give the designer appropriate information to optimize the mix design of CBEMs in a relatively short time.

5. Based on the optimization by RSM, it can be concluded that the optimum mix design proportions (BEC and PWC) tend to be only slightly influenced by CT.

\section{Acknowledgments}

The authors would like to acknowledge the University of Nottingham which has funded this research through the Dean of Engineering Research Scholarship for International Excellence. The authors wish to express their sincere gratitude to the technicians at the Nottingham Transportation Engineering Centre for their support and assistance. 


\section{References}

[1] Thanaya I. Improving the performance of cold bituminous emulsion mixtures (CBEMs): incorporating waste [PhD thesis]: University of Leeds, UK; 2003.

[2] Gómez-Meijide B, Pérez I. A proposed methodology for the global study of the mechanical properties of cold asphalt mixtures. Materials \& Design. 2014;57(0):520-7.

[3] Liebenberg J, Visser A. Towards a mechanistic structural design procedure for emulsiontreated base layers: technical paper. Journal of the South African Institution of Civil Engineering. 2004;46(3):p. 2-9.

[4] Brayton TE, Lee K, Gress D, Harrington J. Development of performance-based mix design for Cold in-Place Recycling of asphalt mixtures. 80th Annual Meeting of the Transportation Research Board. Washington, D.C.,USA 2000.

[5] Asphalt Institute. Asphalt Cold Mix Manual. Series No 14. Maryland, USA1989.

[6] Sebaaly PE, Bazi G, Hitti E, Weitzel D, Bemanian S. Performance of cold in-place recycling in Nevada. 83th Annual Meeting of the Transportation Research Board. Washington DC, USA 2004. p. 162-9.

[7] Kim Y, Lee HD, Heitzman M. Validation of new mix design procedure for cold in-place recycling with foamed asphalt. Journal of Materials in Civil Engineering. 2007;19(11):100010.

[8] Forth J, Zoorob S, Thanaya I. Development of bitumen-bound waste aggregate building blocks. Proceedings of the ICE-Construction Materials. London, UK 2006. p. 23-32.

[9] Montgomery DC. Design and analysis of experiments. 7 th ed. New York, USA: John Wiley \& Sons, Inc; 2008.

[10] Khuri AI, Cornell JA. Response surfaces: designs and analyses. 2nd ed. New York, USA: Marcel Dekker, Inc; 1996.

[11] Bayramov F, Taşdemir C, Taşdemir MA. Optimisation of steel fibre reinforced concretes by means of statistical response surface method. Cement and Concrete Composites. 2004;26(6):665-75.

[12] Aldahdooh M, Muhamad Bunnori N, Megat Johari M. Evaluation of ultra-highperformance-fiber reinforced concrete binder content using the response surface method. Materials \& Design. 2013;52:957-65.

[13] Bektas F, Bektas BA. Analyzing mix parameters in ASR concrete using response surface methodology. Construction and Building Materials. 2014;66:299-305.

[14] Faseeulla Khan MD, Dwivedi DK, Sharma S. Development of response surface model for tensile shear strength of weld-bonds of aluminium alloy 6061 T651. Materials \& Design. 2012;34(0):673-8.

[15] Nekahi A, Dehghani K. Modeling the thermomechanical effects on baking behavior of low carbon steels using response surface methodology. Materials \& Design. 2010;31(8):3845-51.

[16] Younesi M, Bahrololoom ME. Formulating the effects of applied temperature and pressure of hot pressing process on the mechanical properties of polypropylenehydroxyapatite bio-composites by response surface methodology. Materials \& Design. 2010;31(10):4621-30.

[17] Chávez-Valencia L, Manzano-Ramírez A, Luna-Barcenas G, Alonso-Guzmán E. Modelling of the performance of asphalt pavement using response surface methodology. Building and environment. 2005;40(8):1140-9.

[18] Haghshenas H, Khodaii A, Mehrara A, Dehnad M, Ahari A. Frequency and temperature interactive effects on hot mix permanent deformation using response surface methodology. Journal of Materials in Civil Engineering. 2013;26(6). 
[19] Hamzah MO, Golchin B, Tye CT. Determination of the optimum binder content of warm mix asphalt incorporating Rediset using response surface method. Construction and Building Materials. 2013;47:1328-36.

[20] Kavussi A, Qorbani M, Khodaii A, Haghshenas H. Moisture susceptibility of warm mix asphalt: A statistical analysis of the laboratory testing results. Construction and Building Materials. 2014;52:511-7.

[21] Khodaii A, Haghshenas H, Kazemi Tehrani H. Effect of grading and lime content on HMA stripping using statistical methodology. Construction and Building Materials. 2012;34:131-5.

[22] Khodaii A, Mousavi E, Khedmati M, Iranitalab A. Identification of dominant parameters for stripping potential in warm mix asphalt using response surface methodology. Materials and Structures. 2015:1-13.

[23] Hamzah MO, Omranian SR, Golchin B, Hainin MRH. Evaluation of Effects of Extended Short-Term Aging on the Rheological Properties of Asphalt Binders at Intermediate Temperatures Using Respond Surface Method. Jurnal Teknologi. 2015;73(4).

[24] Moghaddam TB, Soltani M, Karim MR, Baaj H. Optimization of asphalt and modifier contents for polyethylene terephthalate modified asphalt mixtures using response surface methodology. Measurement. 2015;74:159-69.

[25] Ameri M, Sanij HK, Toolabi S, Hosseini SH. Optimization of The Cold In-Place Recycling Mix Design by Nonlinear Simplex Method. Transportation Research. 2012;2(1):1.

[26] Gómez-Meijide B, Pérez I. Effects of the use of construction and demolition waste aggregates in cold asphalt mixtures. Construction and Building Materials. 2014;51(0):267-77. [27] Jenkins K, Moloto P. Updating bituminous stabilized materials guidelines: mix design report. Phase II-Curing protocol: improvement. Technical memorandum task 7; 2008.

[28] Loizos A. In-situ characterization of foamed bitumen treated layer mixes for heavy-duty pavements. International Journal of Pavement Engineering. 2007;8(2):123-35.

[29] Konrad J-M, Walter J. Influence of curing on the mechanical properties of a dense graded emulsion mix. Road Materials and Pavement Design. 2001;2(2):181-94.

[30] Ojum C, Kuna K, Thom NH, Airey G. An investigation into the effects of accelerated curing on Cold Recycled Bituminous Mixes. International Conference on Asphalt Pavements, ISAP. North Carolina, USA 2014. p. 1177-88.

[31] Oke OL. A study on the development of guidelines for the production of bitumen emulsion stabilised RAPs for roads in the tropics [PhD thesis]: University of Nottingham, UK; 2011.

[32] European Committee for Standarization. BS 4987-1: Coated macadam (asphalt concrete) for roads and other paved areas. Part 1: Specification for constituent materials and for mixtures. London, UK British Standards Institution; 2005.

[33] Sunarjono S. The influence of foamed bitumen characteristics on cold-mix asphalt properties [PhD Thesis]: University of Nottingham, UK; 2008.

[34] European Committee for Standarization. BS EN 12697-26: Bituminous mixtures: Test methods for hot mix asphalt. Part 26: Stiffness. London, UK British Standards Institution; 2012.

[35] European Committee for Standarization. BS EN 12697-23:Test methods for hot mix asphalt. . Part 23: Determination of the indirect tensile strength of bituminous specimens. London, UK British Standards Institution; 2003.

[36] Doyle T, Gibney A, Mcnally C, Tabakovic A. Developing maturity methods for the assessment of cold-mix bituminous materials. Construction and Building Materials. 2013;38:524-9.

[37] Needham D. Developments in bitumen emulsion mixtures for roads [PhD thesis]: University of Nottingham,UK; 1996. 
[38] García A, Lura P, Partl MN, Jerjen I. Influence of cement content and environmental humidity on asphalt emulsion and cement composites performance. Materials and structures. 2013;46(8):1275-89.

[39] South African Bitumen Association. ETB-The design and use of emulsion-treated bases. SABITA Manual 21. Cape Town, South Africa 1999.

[40] Al-Busaltan S, Al Nageim H, Atherton W, Sharples G. Mechanical Properties of an Upgrading Cold-Mix Asphalt Using Waste Materials. Journal of Materials in Civil Engineering. 2012;24(12):1484-91.

[41] Wang J-P, Chen Y-Z, Wang Y, Yuan S-J, Yu H-Q. Optimization of the coagulationflocculation process for pulp mill wastewater treatment using a combination of uniform design and response surface methodology. Water Research. 2011;45(17):5633-40.

[42] Muralidhar R, Chirumamila R, Marchant R, Nigam P. A response surface approach for the comparison of lipase production by Candida cylindracea using two different carbon sources. Biochemical Engineering Journal. 2001;9(1):17-23.

[43] Noordin MY, Venkatesh VC, Sharif S, Elting S, Abdullah A. Application of response surface methodology in describing the performance of coated carbide tools when turning AISI 1045 steel. Journal of Materials Processing Technology. 2004;145(1):46-58.

[44] Younis SA, El-Azab WI, El-Gendy NS, Aziz SQ, Moustafa YM, Aziz HA, et al. Application of Response Surface Methodology to Enhance Phenol Removal from Refinery Wastewater by Microwave Process. International Journal of Microwave Science and Technology. 2014. 